\title{
List of Drugs in Development for Neurodegenerative Diseases
}

\section{Update June 2004}

\section{Myoung-Ok Kwon $^{a}$ Frauke Fischer $^{b}$ Mark Matthisson $^{b}$ Paul Herrling ${ }^{a}$}

${ }^{\text {a }}$ Corporate Research, Novartis International AG; ${ }^{b}$ Novartis Pharma AG, Basel, Switzerland

Neurodegenerative diseases are an increasingly important issue in our society. There are, however, still many obstacles on the way to finding methods for cure. This table is intended to give an overview over neurodegenerative drugs that are currently in research and development in order to give the reader an idea about the complexity of drug discovery in this field. This table is intended as a pointer to drugs and it is recommended to obtain additional information from the internet to check for newest developments.

\begin{tabular}{|c|c|c|c|c|c|c|}
\hline & $\begin{array}{l}\text { Highest dev. } \\
\text { status }\end{array}$ & Company & Drug & Indication & Mode of action & Drug effect \\
\hline 1 & Discovery & $\begin{array}{l}\text { University of South } \\
\text { Florida }\end{array}$ & $\begin{array}{l}\text { (-)-epigallocatechin- } \\
\text { 3-gallate }\end{array}$ & $\begin{array}{l}\text { Neurodegenerative } \\
\text { disease }\end{array}$ & $\begin{array}{l}\text { IL synthesis modulator; } \\
\text { Protein kinase C } \\
\text { modulator; TACE } \\
\text { modulator }\end{array}$ & Cell cycle inhibitor \\
\hline 2 & Discovery & $\begin{array}{l}\text { Fujimoto Seiyaku Co } \\
\text { Ltd }\end{array}$ & $\begin{array}{l}\text { (R)-(-)-BPAP } \\
\end{array}$ & $\begin{array}{l}\text { Neurodegenerative } \\
\text { disease }\end{array}$ & $\begin{array}{l}\text { Neurotransmitter } \\
\text { modulator }\end{array}$ & Neuroprotectant \\
\hline 3 & $\begin{array}{l}* * \text { Phase } 1 \\
\text { Clinical }\end{array}$ & GlaxoSmithKline plc & 644784 & Pain; Schizophrenia & $\begin{array}{l}\text { Cyclooxygenase } 2 \\
\text { inhibitor }\end{array}$ & $\begin{array}{l}\text { Antipsychotic; } \\
\text { Analgesic }\end{array}$ \\
\hline 4 & $\begin{array}{l}* * \text { Phase } 1 \\
\text { Clinical }\end{array}$ & GlaxoSmithKline plc & 742457 & $\begin{array}{l}\text { Alzheimers disease; } \\
\text { Schizophrenia }\end{array}$ & 5-HT 6 antagonist & Antipsychotic \\
\hline 5 & $\begin{array}{l}* * \text { Phase } 1 \\
\text { Clinical }\end{array}$ & GlaxoSmithKline plc & 773812 & Schizophrenia & $\begin{array}{l}\text { 5-HT antagonist; } \\
\text { Dopamine modulator }\end{array}$ & Antipsychotic \\
\hline 6 & $\begin{array}{l}* * \text { Phase } 2 \\
\text { Clinical }\end{array}$ & $\begin{array}{l}\text { Aventis } \\
\text { Pharmaceuticals Inc }\end{array}$ & 100907 & $\begin{array}{l}\text { Schizoaffective } \\
\text { disorder; Anxiety } \\
\text { disorder; Psychosis; } \\
\text { Schizophrenia; Sleep } \\
\text { disorder; Major } \\
\text { depressive disorder }\end{array}$ & 5-HT 2a antagonist & Antipsychotic \\
\hline 7 & $\begin{array}{l}* \text { Discontinued } \\
\text { (Phase } 2 \\
\text { Clinical) }\end{array}$ & Carlbiotech Ltd & $106362-32-7$ & $\begin{array}{l}\text { HIV associated } \\
\text { dementia; } \\
\text { Neurodegenerative } \\
\text { disease }\end{array}$ & peptide -T & Nootropic agent \\
\hline
\end{tabular}

\footnotetext{
* Changes made from last issue; ** newly added drug.
}

\section{KARGER}

Fax +41613061234 E-Mail karger@karger.ch www.karger.com 


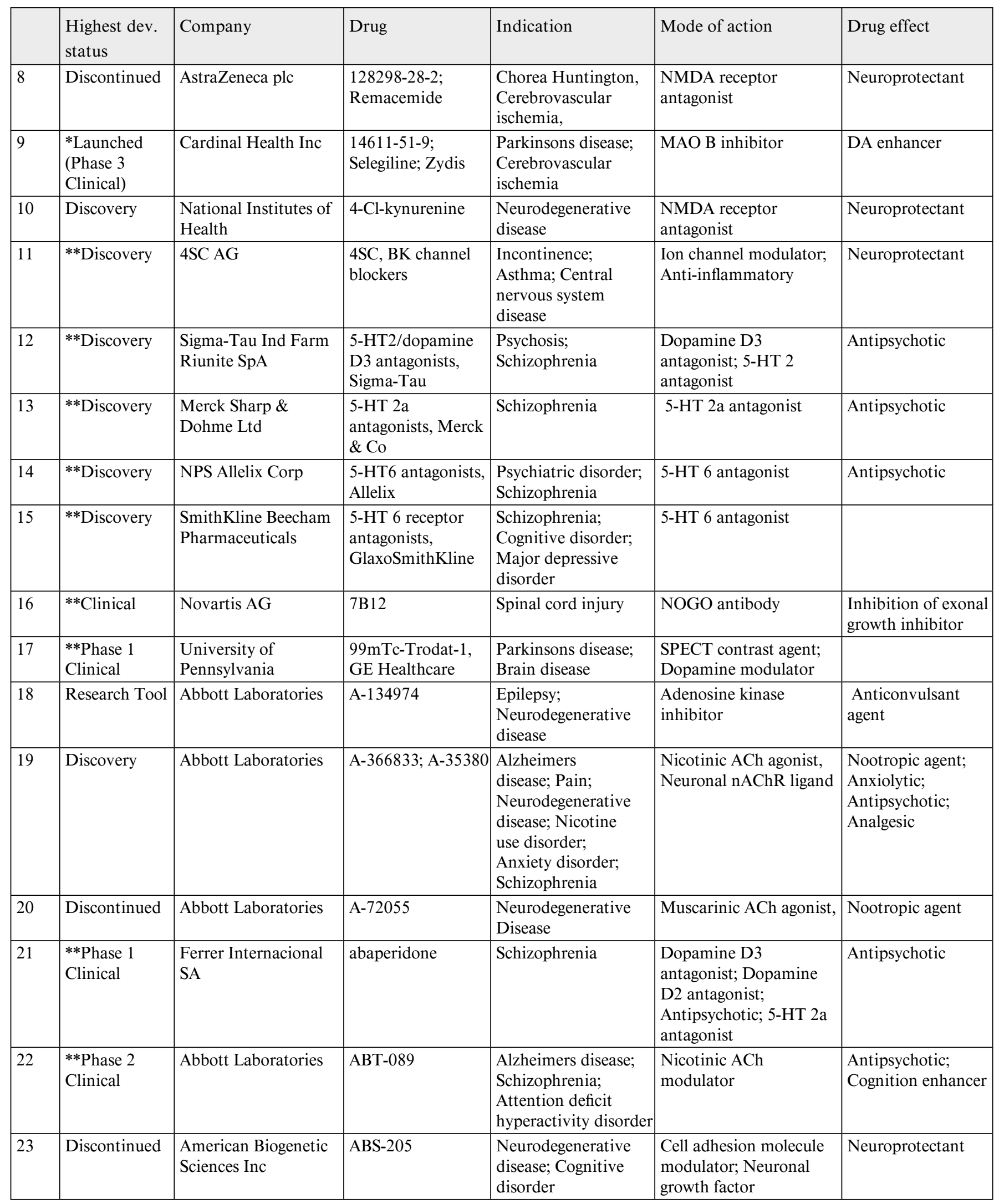




\begin{tabular}{|c|c|c|c|c|c|c|}
\hline & $\begin{array}{l}\text { Highest dev. } \\
\text { status }\end{array}$ & Company & Drug & Indication & Mode of action & Drug effect \\
\hline 24 & Discovery & $\begin{array}{l}\text { ACADIA } \\
\text { Pharmaceuticals Inc }\end{array}$ & AC-184897 & $\begin{array}{l}\text { Neurodegenerative } \\
\text { disease; Carcinoma }\end{array}$ & Nuclear receptor agonists & $\begin{array}{l}\text { Anticancer; } \\
\text { Neuroprotectant }\end{array}$ \\
\hline 25 & Discovery & $\begin{array}{l}\text { ACADIA } \\
\text { Pharmaceuticals Inc }\end{array}$ & AC-90222 & Alzheimers Disease & Muscarinic M1 agonist & Nootropic agent \\
\hline 26 & Discontinued & Cocensys Inc, Novartis & ACEA-1021 & \begin{tabular}{|l|} 
Epilepsy; Head \\
trauma; Pain
\end{tabular} & $\begin{array}{l}\text { NMDA,/ Glycine } \\
\text { antagonist }\end{array}$ & $\begin{array}{l}\text { Neuroprotectant, } \\
\text { Anticonvulsant }\end{array}$ \\
\hline 27 & **Discovery & Synaptica Ltd & \begin{tabular}{|l|} 
AChE peptide \\
fragment \\
(neurodegenerative \\
disease), Synaptica \\
\end{tabular} & $\begin{array}{l}\text { Alzheimers disease; } \\
\text { Motor neurone } \\
\text { disease; Parkinsons } \\
\text { disease }\end{array}$ & $\begin{array}{l}\text { Acetylcholinesterase } \\
\text { modulator }\end{array}$ & $\begin{array}{l}\text { Antiparkinsonian; } \\
\text { Neuroprotectant }\end{array}$ \\
\hline 28 & $\begin{array}{l}* * \text { Phase } 1 \\
\text { Clinical }\end{array}$ & $\begin{array}{l}\text { ACADIA } \\
\text { Pharmaceuticals Inc }\end{array}$ & ACP-103 & $\begin{array}{l}\text { Psychosis; } \\
\text { Schizophrenia }\end{array}$ & $\begin{array}{l}\text { 5-HT 2c receptor } \\
\text { modulator; 5-HT 2a } \\
\text { receptor modulator; } \\
\text { 5-HT 2a antagonist }\end{array}$ & Antipsychotic \\
\hline 30 & **Discovery & $\begin{array}{l}\text { Prescient } \\
\text { NeuroPharma Inc }\end{array}$ & $\begin{array}{l}\text { ACPD analogs, } \\
\text { IGT }\end{array}$ & $\begin{array}{l}\text { Epilepsy; } \\
\text { Anxiety disorder; } \\
\text { Cerebrovascular } \\
\text { ischemia; Head injury }\end{array}$ & $\begin{array}{l}\text { Metabotropic glutamate } \\
\text { receptor } 1 \text { agonist; } \\
\text { Metabotropic glutamate } \\
\text { receptor } 2 \text { agonist }\end{array}$ & $\begin{array}{l}\text { Neuroprotectant; } \\
\text { Anxiolytic; } \\
\text { Anticonvulsant } \\
\text { agent }\end{array}$ \\
\hline 31 & $\begin{array}{l}* \text { Discontinued } \\
\text { (Discovery) }\end{array}$ & $\begin{array}{l}\text { National Institutes of } \\
\text { Health }\end{array}$ & ADCI & $\begin{array}{l}\text { Neurodegenerative } \\
\text { disease }\end{array}$ & $\begin{array}{l}\text { NMDA and sodium } \\
\text { channel antagonist }\end{array}$ & $\begin{array}{l}\text { Neuroprotectant; } \\
\text { Anticonvulsant } \\
\text { agent }\end{array}$ \\
\hline 32 & **Discovery & $\begin{array}{l}\text { ActinoDrug } \\
\text { Pharmaceuticals } \\
\text { GmBH }\end{array}$ & AD-GL0002 & $\begin{array}{l}\text { Parkinsons disease; } \\
\text { Cancer; Cirrhosis }\end{array}$ & $\begin{array}{l}\text { IL-6 synthesis inhibitor; } \\
\text { Transcription factor } \\
\text { inhibitor }\end{array}$ & $\begin{array}{l}\text { Anticancer; } \\
\text { Antiparkinsonian }\end{array}$ \\
\hline 35 & **Discovery & Genentech Inc & $\begin{array}{l}\text { agonist trkC } \\
\text { monoclonal } \\
\text { antibody, } \\
\text { Genentech }\end{array}$ & Neuropathy & $\begin{array}{l}\text { Protein tyrosine kinase } \\
\text { modulator }\end{array}$ & Neuroprotectant \\
\hline 36 & Discovery & AGY Therapeutics & AGY-110 & $\begin{array}{l}\text { Alzheimers disease; } \\
\text { Schizophrenia, Major } \\
\text { depressive disorder }\end{array}$ & $\begin{array}{l}\text { Unclassified enzyme } \\
\text { inhibitor }\end{array}$ & Nootropic agent \\
\hline 37 & Discovery & AGY Therapeutics & AGY-207 & $\begin{array}{l}\text { Cerebrovascular } \\
\text { ischemia }\end{array}$ & $\begin{array}{l}\text { Unclassified enzyme } \\
\text { inhibitor }\end{array}$ & Neuroprotectant \\
\hline 38 & \begin{tabular}{|l} 
No \\
Development \\
Reported \\
\end{tabular} & Cortex/Alkermes & AK-275; Vasolex & $\begin{array}{l}\text { Cerebral infarction; } \\
\text { Ischemia }\end{array}$ & Calpain inhibitor & $\begin{array}{l}\text { Neuroprotectant; } \\
\text { Vasoprotectant }\end{array}$ \\
\hline 39 & $\begin{array}{l}\text { Phase } 2 \\
\text { Clincial }\end{array}$ & VUFB & Alaptid & Alzheimers disease & $\begin{array}{l}\text { Melanotropin-inhibiting } \\
\text { factor (MIF)-1 analog }\end{array}$ & Nootropic agent \\
\hline
\end{tabular}




\begin{tabular}{|c|c|c|c|c|c|c|}
\hline & $\begin{array}{l}\text { Highest dev. } \\
\text { status }\end{array}$ & Company & Drug & Indication & Mode of action & Drug effect \\
\hline 40 & $\begin{array}{l}\text { No } \\
\text { Development } \\
\text { Reported }\end{array}$ & NPS Allelix Corp & ALE-0540 & \begin{tabular}{|l|} 
Nervous system \\
injury; Pain; \\
Neurodegenerative \\
disease \\
\end{tabular} & NGF antagonist & $\begin{array}{l}\text { Neuroprotectant; } \\
\text { Analgesic }\end{array}$ \\
\hline 41 & **Discovery & \begin{tabular}{|l|} 
Memory \\
Pharmaceuticals Corp
\end{tabular} & $\begin{array}{l}\text { alpha-7 partial } \\
\text { agonists, Memory }\end{array}$ & $\begin{array}{l}\text { Alzheimers disease; } \\
\text { Schizophrenia; } \\
\text { Central nervous } \\
\text { system disease }\end{array}$ & $\begin{array}{l}\text { Nicotinic ACh } \\
\text { modulator }\end{array}$ & Nootropic agent \\
\hline 42 & **Discovery & $\begin{array}{l}\text { University of } \\
\text { Queensland }\end{array}$ & $\begin{array}{l}\text { alpha-conotoxins, } \\
\text { University of } \\
\text { Queensland }\end{array}$ & Neurological disease & Nicotinic ACh antagonist & Muscle relaxant \\
\hline 43 & **Discovery & $\begin{array}{l}\text { Isis Pharmaceuticals } \\
\text { Inc }\end{array}$ & $\begin{array}{l}\text { ALS antisense } \\
\text { therapeutics, Isis }\end{array}$ & $\begin{array}{l}\text { Motor neurone } \\
\text { disease }\end{array}$ & $\begin{array}{l}\text { Superoxide dismutase } \\
\text { inhibitor; Antisense } \\
\text { oligonucleotide inhibitor }\end{array}$ & Neuroprotectant \\
\hline 44 & $\begin{array}{l}* * \text { Phase } 3 \\
\text { Clincial }\end{array}$ & $\begin{array}{l}\text { Harvard University/ } \\
\text { Boston Life Sciences } \\
\text { Inc }\end{array}$ & Altropane & \begin{tabular}{|l|} 
Parkinsons disease; \\
Attention deficit \\
hyperactivity disorder
\end{tabular} & $\begin{array}{l}\text { Dopamine transporter } \\
\text { ligand, }{ }^{123} \text { I labelled }\end{array}$ & $\begin{array}{l}\text { Diagnostic/Imaging } \\
\text { agent }\end{array}$ \\
\hline 45 & $* *$ Discovery & $\begin{array}{l}\text { University of } \\
\text { Georgetown }\end{array}$ & $\begin{array}{l}\text { Alzheimers disease } \\
\text { therapeutic, } \\
\text { Georgetown/ } \\
\text { Samaritan }\end{array}$ & $\begin{array}{l}\text { Spinal cord injury; } \\
\text { Alzheimers disease; } \\
\text { Neurodegenerative } \\
\text { disease; Parkinsons } \\
\text { disease; Dementia }\end{array}$ & CNS modulator & $\begin{array}{l}\text { Neuroprotectant; } \\
\text { Antiparkinsonian }\end{array}$ \\
\hline 46 & **Discovery & Pharmexa A/S & $\begin{array}{l}\text { Alzheimers } \\
\text { vaccine (AutoVac), } \\
\text { Pharmexa/ } \\
\text { Lundbeck }\end{array}$ & Alzheimers disease & $\begin{array}{l}\text { Vaccine; Target not } \\
\text { disclosed }\end{array}$ & Neuroprotectant \\
\hline 47 & Discovery & AMRAD Corp Ltd & AM-36 & \begin{tabular}{|l|} 
Cerebrovascular \\
ischemia; Alzheimers \\
disease, Spinal chord \\
injury
\end{tabular} & Sodium channel blocker & $\begin{array}{l}\text { Neuroprotectant; } \\
\text { Antioxidant agent }\end{array}$ \\
\hline 48 & Discovery & Annovis Inc & $\begin{array}{l}\text { AMPA antagonists, } \\
\text { Annovis }\end{array}$ & $\begin{array}{l}\text { Epilepsy; } \\
\text { Neurodegenerative } \\
\text { disease; } \\
\text { Schizophrenia; } \\
\text { Cerebrovascular } \\
\text { ischemia }\end{array}$ & $\begin{array}{l}\text { AMPA receptor } \\
\text { antagonist }\end{array}$ & $\begin{array}{l}\text { Neuroprotectant; } \\
\text { Antipsychotic; } \\
\text { Anticonvulsant } \\
\text { agent }\end{array}$ \\
\hline 49 & **Discovery & Eli Lilly \& Co & $\begin{array}{l}\text { AMPA modulators, } \\
\text { Lilly/NPS }\end{array}$ & Cognitive disorder & $\begin{array}{l}\text { AMPA receptor } \\
\text { modulator }\end{array}$ & Cognition enhancer \\
\hline 50 & **Discovery & NV Organon & $\begin{array}{l}\text { AMPA modulators, } \\
\text { Organon }\end{array}$ & $\begin{array}{l}\text { Alzheimers disease; } \\
\text { Schizophrenia; } \\
\text { Cognitive disorder } \\
\end{array}$ & $\begin{array}{l}\text { AMPA receptor } \\
\text { modulator }\end{array}$ & Antipsychotic \\
\hline 51 & **Discovery & Eisai Co Ltd & $\begin{array}{l}\text { AMPA receptor } \\
\text { antagonists } \\
\text { (Multiple sclerosis), } \\
\text { Eisai }\end{array}$ & Multiple sclerosis & $\begin{array}{l}\text { AMPA receptor } \\
\text { antagonist }\end{array}$ & Neuroprotectant \\
\hline 52 & **Discovery & $\begin{array}{l}\text { Yamanouchi } \\
\text { Pharmaceutical Co } \\
\text { Ltd }\end{array}$ & $\begin{array}{l}\text { AMPA receptor } \\
\text { antagonists, } \\
\text { Yamanouchi }\end{array}$ & $\begin{array}{l}\text { Central nervous } \\
\text { system disease }\end{array}$ & $\begin{array}{l}\text { AMPA receptor } \\
\text { antagonist }\end{array}$ & Neuroprotectant \\
\hline 53 & Discovery & \begin{tabular}{|l|} 
University of \\
California; Cortex; NV \\
Organon; Servier
\end{tabular} & AMPAKINES & $\begin{array}{l}\text { Dementia; } \\
\text { Schizophrenia; } \\
\text { Alzheimers disease }\end{array}$ & $\begin{array}{l}\text { AMPA receptor } \\
\text { modulator }\end{array}$ & $\begin{array}{l}\text { Neuroprotectant; } \\
\text { Antidepressant, } \\
\text { Antipsychotic }\end{array}$ \\
\hline
\end{tabular}




\begin{tabular}{|c|c|c|c|c|c|c|}
\hline & $\begin{array}{l}\text { Highest dev. } \\
\text { status }\end{array}$ & Company & Drug & Indication & Mode of action & Drug effect \\
\hline 54 & $\begin{array}{l}\text { Phase } 1 \\
\text { Clinical }\end{array}$ & Axonyx Inc / Serono & $\begin{array}{l}\text { Amyloid-inhibiting } \\
\text { peptides }\end{array}$ & $\begin{array}{l}\text { Alzheimers disease; } \\
\text { Neurodegenerative } \\
\text { disease }\end{array}$ & $\begin{array}{l}\text { Beta amyloid generation } \\
\text { inhibitor }\end{array}$ & Anti-amyloidogenic \\
\hline 55 & Discontinued & $\begin{array}{l}\text { Elan Pharmaceuticals } \\
\text { Inc }\end{array}$ & AN-1792 & Alzheimers disease & $\begin{array}{l}\text { Synthetic beta amyloid; } \\
\text { Vaccine }\end{array}$ & $\begin{array}{l}\text { beta amyloid } \\
\text { vaccine agonist }\end{array}$ \\
\hline 57 & Discovery & Paracelsian Inc & Andrographolide & $\begin{array}{l}\text { Neurodegenerative } \\
\text { disease }\end{array}$ & Herbal product & $\begin{array}{l}\text { Neuroprotectant; } \\
\text { Anti-inflammatory }\end{array}$ \\
\hline 58 & $\begin{array}{l}\text { Phase } 3 \\
\text { Clinical }\end{array}$ & $\begin{array}{l}\text { Apollo } \\
\text { Biopharmaceutics } \\
\text { Inc / Wyeth }\end{array}$ & $\begin{array}{l}\text { APBPI-124 / } \\
\text { estrogen-like } \\
\text { compounds }\end{array}$ & $\begin{array}{l}\text { Alzheimers disease; } \\
\text { Neurodegenerative } \\
\text { disease; Parkinsons } \\
\text { disease; } \\
\text { Cerebrovascular } \\
\text { ischemia }\end{array}$ & Estrogen modulator & $\begin{array}{l}\text { Neuroprotectant; } \\
\text { Antiparkinsonian }\end{array}$ \\
\hline 59 & $\begin{array}{l}* * \text { Phase } 2 \\
\text { Clinical }\end{array}$ & $\begin{array}{l}\text { Britannia } \\
\text { Pharmaceuticals Ltd }\end{array}$ & $\begin{array}{l}\text { apomorphine } \\
\text { (nasal; ED), } \\
\text { Britannia } \\
\end{array}$ & $\begin{array}{l}\text { Erectile dysfunction; } \\
\text { Parkinsons disease }\end{array}$ & Dopamine agonist & $\begin{array}{l}\text { Antiparkinsonian; } \\
\text { Apomorphine } \\
\text { modulator }\end{array}$ \\
\hline 60 & **Discovery & \begin{tabular}{|l|} 
Merck Sharp \& \\
Dohme Ltd
\end{tabular} & $\begin{array}{l}\text { apopain inhibitors, } \\
\text { Merck Sharp }\end{array}$ & $\begin{array}{l}\text { Neurodegenerative } \\
\text { disease }\end{array}$ & $\begin{array}{l}\text { Cysteine protease } \\
\text { inhibitor }\end{array}$ & Apoptosis inhibitor \\
\hline 61 & \begin{tabular}{|l|} 
No \\
Development \\
Reported \\
\end{tabular} & ImmunoGen Inc & apoptosin & $\begin{array}{l}\text { Neurodegenerative } \\
\text { disease }\end{array}$ & & $\begin{array}{l}\text { Apoptosis } \\
\text { modulator }\end{array}$ \\
\hline 62 & $\begin{array}{l}\text { No } \\
\text { Development } \\
\text { Reported }\end{array}$ & $\begin{array}{l}\text { Oregon Health } \\
\text { Sciences University }\end{array}$ & Aptiganel & \begin{tabular}{|l|} 
Neurodegenerative \\
disease; Parkinsons \\
disease; \\
Cerebrovascular \\
disease; \\
Cerebrovascular \\
ischemia; Brain injury
\end{tabular} & $\begin{array}{l}\text { NMDA receptor } \\
\text { antagonist, Ionotropic } \\
\text { glutamate receptor } \\
\text { antagonist }\end{array}$ & $\begin{array}{l}\text { Neuroprotectant; } \\
\text { Antiparkinsonian }\end{array}$ \\
\hline 64 & Discontinued & Fisons plc & $\begin{array}{l}\text { AR-15896; } \\
\text { lanicemine }\end{array}$ & $\begin{array}{l}\text { Cerebral infarction; } \\
\text { Ischemia }\end{array}$ & $\begin{array}{l}\text { NMDA receptor } \\
\text { antagonist }\end{array}$ & Neuroprotectant \\
\hline 65 & Discovery & AstraZeneca plc & AR-A-008055 & $\begin{array}{l}\text { Neurotoxicity, } \\
\text { drug-induced; } \\
\text { Neurodegenerative } \\
\text { disease }\end{array}$ & GABA A agonist & Neuroprotectant \\
\hline 66 & $\begin{array}{l}\text { *Launched } \\
\text { (Phase } 3 \\
\text { Clinical) }\end{array}$ & Eisai/Pfizer Inc & $\begin{array}{l}\text { Aricept (Donepezil) } \\
\text { vs. a-Tocopherol }\end{array}$ & $\begin{array}{l}\text { Neurodegenerative } \\
\text { disease; Alzheimers } \\
\text { disease }\end{array}$ & $\begin{array}{l}\text { Acetylcholinesterase } \\
\text { inhibitor }\end{array}$ & $\begin{array}{l}\text { Neuroprotectant; } \\
\text { Cognition enhancer }\end{array}$ \\
\hline 67 & Research Tool & AstraZeneca plc & AR-R-17779 & $\begin{array}{l}\text { Alzheimers disease; } \\
\text { Neurodegenerative } \\
\text { disease; Anxiety } \\
\text { disorder }\end{array}$ & ACh agonist & $\begin{array}{l}\text { Nootropic agent; } \\
\text { Anxiolytic }\end{array}$ \\
\hline 68 & $\begin{array}{l}\text { No } \\
\text { Development } \\
\text { Reported }\end{array}$ & AstraZeneca plc & AR-R18565 & Ischemia & Calcium channel blocker & Vasodilatory agent \\
\hline
\end{tabular}




\begin{tabular}{|c|c|c|c|c|c|c|}
\hline & $\begin{array}{l}\text { Highest dev. } \\
\text { status }\end{array}$ & Company & Drug & Indication & Mode of action & Drug effect \\
\hline 69 & $\begin{array}{l}\text { No } \\
\text { Development } \\
\text { Reported }\end{array}$ & Array BioPharma Inc & ARRY-142886 & $\begin{array}{l}\text { Neurodegenerative } \\
\text { disease }\end{array}$ & $\begin{array}{l}\text { Protein kinase inhibitor; } \\
\text { Mek protein kinase } \\
\text { inhibitor }\end{array}$ & Neuroprotectant \\
\hline 70 & Discovery & AlphaRx Inc & $\begin{array}{l}\text { ARX-2000; -2001; } \\
\text {-2002; AlphaRx }\end{array}$ & $\begin{array}{l}\text { Inflammation; } \\
\text { Neurodegenerative } \\
\text { disease; Immune } \\
\text { deficiency }\end{array}$ & Immunomodulators & Immunostimulant \\
\hline 71 & $\begin{array}{l}* * \text { Phase } 3 \\
\text { Clinical }\end{array}$ & NV Organon & asenapine & $\begin{array}{l}\text { Psychosis; } \\
\text { Schizophrenia }\end{array}$ & $\begin{array}{l}\text { Dopamine D1 } \\
\text { antagonist; Dopamine } \\
\text { D2 antagonist; 5-HT 2a } \\
\text { antagonist } \\
\end{array}$ & Antipsychotic \\
\hline 72 & Discovery & Serono SA & $\begin{array}{l}\text { AS-600292; AS- } \\
\text { 004509; AS-601245 }\end{array}$ & $\begin{array}{l}\text { Chronic obstructive } \\
\text { pulmonary disease; } \\
\text { Inflammation; } \\
\text { Inflammatory } \\
\text { bowel disease; } \\
\text { Multiple sclerosis; } \\
\text { Neurodegenerative } \\
\text { disease; Rheumatoid } \\
\text { arthritis; Asthma; } \\
\text { Central nervous } \\
\text { system disease; } \\
\text { Ischemia }\end{array}$ & $\begin{array}{l}\text { Jun } \mathrm{N} \text { terminal kinase } \\
\text { modulator; Jun } \mathrm{N} \\
\text { terminal kinase-2 } \\
\text { inhbitor; Jun N terminal } \\
\text { kinase-3a inhibitor }\end{array}$ & $\begin{array}{l}\text { Vasoprotectant; } \\
\text { Anti-inflammatory }\end{array}$ \\
\hline 73 & **Discovery & Avigen Inc & AV-201 & Parkinsons disease & $\begin{array}{l}\text { Dopamine synthesis } \\
\text { modulator; Adeno- } \\
\text { associated virus based } \\
\text { gene therapy }\end{array}$ & Antiparkinsonian \\
\hline 76 & $\begin{array}{l}\text { No } \\
\text { Development } \\
\text { Reported }\end{array}$ & $\begin{array}{l}\text { Regeneron } \\
\text { Pharmaceuticals Inc }\end{array}$ & Axokine & $\begin{array}{l}\text { Huntingtons } \\
\text { chorea; Motor } \\
\text { neurone disease; } \\
\text { Neurodegenerative } \\
\text { disease }\end{array}$ & CNTF agonist & $\begin{array}{l}\text { Metabolic } \\
\text { modulator }\end{array}$ \\
\hline 77 & **Discovery & $\begin{array}{l}\text { Acorda Therapeutics } \\
\text { Inc }\end{array}$ & $\begin{array}{l}\text { axonal guidance } \\
\text { proteins, Acorda }\end{array}$ & $\begin{array}{l}\text { Spinal cord injury; } \\
\text { Parkinsons disease }\end{array}$ & $\begin{array}{l}\text { Cell adhesion } \\
\text { molecule modulator; } \\
\text { Antiparkinsonian }\end{array}$ & Neuroprotectant \\
\hline 78 & $\begin{array}{l}\text { No } \\
\text { Development } \\
\text { Reported }\end{array}$ & Asahi Kasei Corp & AZ-36041 & $\begin{array}{l}\text { Alzheimers disease; } \\
\text { Neurodegenerative } \\
\text { disease }\end{array}$ & $\begin{array}{l}\text { Reduction of amyloid } \\
\text { beta }\end{array}$ & Neuroprotectant \\
\hline 79 & *Discovery & AstraZeneca plc & AZD-0328 & $\begin{array}{l}\text { Alzheimers disease; } \\
\text { Cognitive disorder }\end{array}$ & $\begin{array}{l}\text { 5-HT } 3 \text { agonist; } \\
\text { Nicotinic ACh agonist }\end{array}$ & $\begin{array}{l}\text { Nootropic agent; } \\
\text { Anxiolytic }\end{array}$ \\
\hline 80 & Discovery & $\begin{array}{l}\text { BioAxone } \\
\text { Therapeutique Inc }\end{array}$ & BA-1016 & $\begin{array}{l}\text { Neurodegenerative } \\
\text { disease; } \\
\text { Cerebrovascular } \\
\text { ischemia; Cancer }\end{array}$ & Rho kinase inhibitor & $\begin{array}{l}\text { Anticancer; } \\
\text { Neuroprotectant }\end{array}$ \\
\hline
\end{tabular}




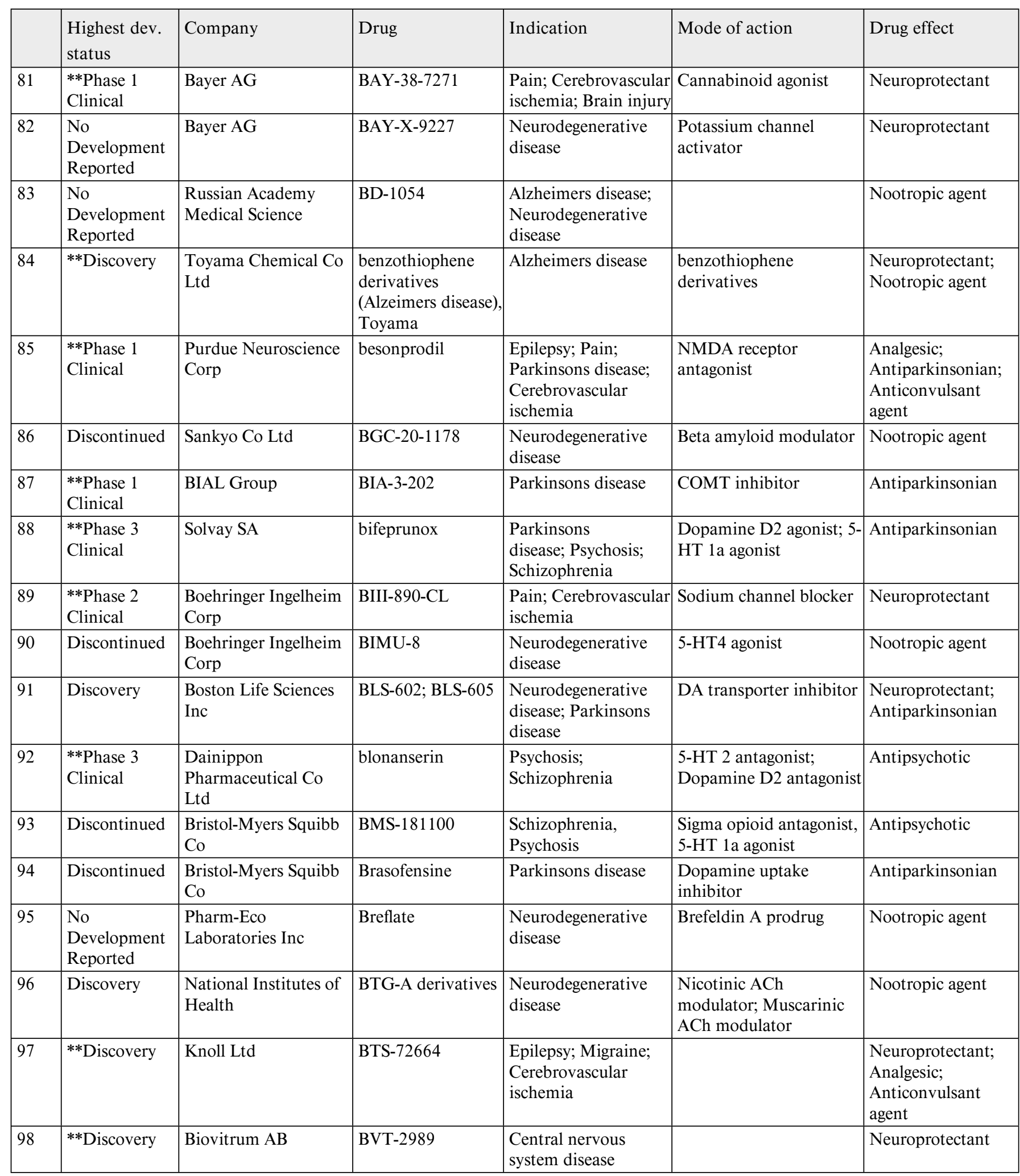




\begin{tabular}{|c|c|c|c|c|c|c|}
\hline & $\begin{array}{l}\text { Highest dev. } \\
\text { status }\end{array}$ & Company & Drug & Indication & Mode of action & Drug effect \\
\hline 99 & **Discovery & $\begin{array}{l}\text { OXIS International } \\
\text { Inc }\end{array}$ & BXT-51072 & $\begin{array}{l}\text { Chronic obstructive } \\
\text { pulmonary disease; } \\
\text { Inflammatory } \\
\text { bowel disease; } \\
\text { Asthma; Restenosis; } \\
\text { Ulcerative colitis; } \\
\text { Cerebrovascular } \\
\text { ischemia; Respiratory } \\
\text { distress syndrome }\end{array}$ & Glutathione modulator & $\begin{array}{l}\text { Neuroprotectant; } \\
\text { Vasoprotectant }\end{array}$ \\
\hline 100 & **Discovery & $\begin{array}{l}\text { BioCryst } \\
\text { Pharmaceuticals Inc }\end{array}$ & \begin{tabular}{|l|} 
C1s inhibitors, \\
3-Dimensional \\
Pharmaceuticals/ \\
BioCryst
\end{tabular} & \begin{tabular}{|l|} 
Inflammation; \\
Myocardial \\
infarction; Systemic \\
lupus erythematosus; \\
Autoimmune disease; \\
Cerebrovascular \\
ischemia; Respiratory \\
distress syndrome
\end{tabular} & $\begin{array}{l}\text { Anti-inflammatory; } \\
\text { Serine protease inhibitor; } \\
\text { Complement cascade } \\
\text { inhibitor }\end{array}$ & $\begin{array}{l}\text { Neuroprotectant; } \\
\text { Cardioprotectant; } \\
\text { Vasoprotectant }\end{array}$ \\
\hline 101 & $\begin{array}{l}\text { No } \\
\text { Development } \\
\text { Reported }\end{array}$ & Roche & C60 fullerenes & $\begin{array}{l}\text { Neurodegenerative } \\
\text { disease; } \\
\text { Cerebrovascular } \\
\text { ischemia; Head injury }\end{array}$ & Free radical scavenger & Neuroprotectant \\
\hline 102 & **Discovery & $\begin{array}{l}\text { Senju Pharmaceutical } \\
\text { Co Ltd }\end{array}$ & $\begin{array}{l}\text { calpain } \\
\text { inhibitors, Senju } \\
\text { Pharmaceutical }\end{array}$ & $\begin{array}{l}\text { Nervous system } \\
\text { injury; Muscular } \\
\text { dystrophy; } \\
\text { Neurodegenerative } \\
\text { disease; Cataract; } \\
\text { Cerebrovascular } \\
\text { ischemia } \\
\end{array}$ & Calpain inhibitor & Neuroprotectant \\
\hline 103 & **Discovery & Genentech Inc & cardiotrophin-1 & $\begin{array}{l}\text { Glaucoma; } \\
\text { Huntingtons chorea; } \\
\text { Motor neurone } \\
\text { disease; Uveitis; } \\
\text { Cardiovascular } \\
\text { disease }\end{array}$ & $\begin{array}{l}\text { Cytokine, growth factor } \\
\text { for myocytes }\end{array}$ & Growth factor \\
\hline 104 & \begin{tabular}{|l|} 
No \\
Development \\
Reported \\
\end{tabular} & Aventis & $\begin{array}{l}\text { CAS-493; } \\
\text { Aloracetam }\end{array}$ & Alzheimers disease & & Nootropic agent \\
\hline 105 & **Discovery & \begin{tabular}{|l|} 
Sunesis \\
Pharmaceuticals Inc
\end{tabular} & $\begin{array}{l}\text { caspase inhibitors, } \\
\text { Sunesis }\end{array}$ & $\begin{array}{l}\text { Inflammation; } \\
\text { Neurodegenerative } \\
\text { disease; } \\
\text { Cardiovascular } \\
\text { disease }\end{array}$ & $\begin{array}{l}\text { Caspase inhibitor; } \\
\text { Antiapoptotic }\end{array}$ & $\begin{array}{l}\text { Nootropic agent; } \\
\text { Anti-inflammatory; } \\
\text { Cardiovascular } \\
\text { agent }\end{array}$ \\
\hline 106 & **Discovery & $\begin{array}{l}\text { Yamanouchi } \\
\text { Pharmaceutical Co } \\
\text { Ltd }\end{array}$ & $\begin{array}{l}\text { caspase-3 } \\
\text { inhibitors, } \\
\text { Yamanouchi }\end{array}$ & $\begin{array}{l}\text { Alzheimers disease; } \\
\text { Liver disease; } \\
\text { Myocardial } \\
\text { infarction; } \\
\text { Parkinsons disease; } \\
\text { Cerebrovascular } \\
\text { ischemia }\end{array}$ & $\begin{array}{l}\text { Caspase inhibitor; } \\
\text { Antiapoptotic }\end{array}$ & $\begin{array}{l}\text { Neuroprotectant; } \\
\text { Cardioprotectant; } \\
\text { Antiparkinsonian }\end{array}$ \\
\hline 107 & **Discovery & $\begin{array}{l}\text { Cognitive } \\
\text { Pharmaceuticals Ltd }\end{array}$ & CDD-0304 & $\begin{array}{l}\text { Alzheimers disease; } \\
\text { Schizophrenia }\end{array}$ & Muscarinic M1 agonist & Nootropic agent \\
\hline 108 & $* *$ Discovery & Novo Nordisk A/S & CEE-03-310 & $\begin{array}{l}\text { Alcoholism; } \\
\text { Schizophrenia; } \\
\text { Sleep disorder; Drug } \\
\text { dependence }\end{array}$ & Dopamine D1 antagonist & Antipsychotic \\
\hline
\end{tabular}




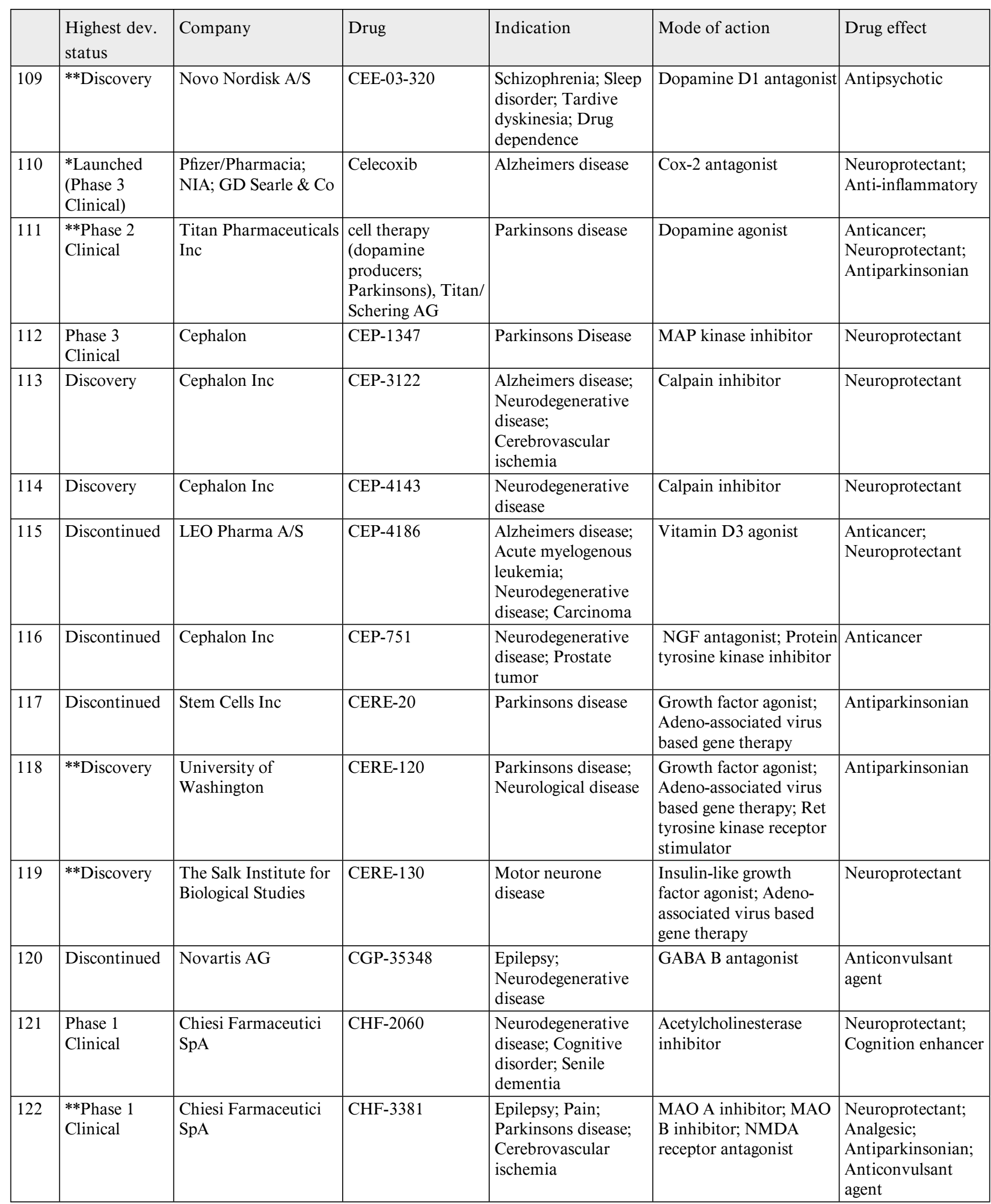




\begin{tabular}{|c|c|c|c|c|c|c|}
\hline & $\begin{array}{l}\text { Highest dev. } \\
\text { status }\end{array}$ & Company & Drug & Indication & Mode of action & Drug effect \\
\hline 123 & $\begin{array}{l}* * \text { Research } \\
\text { Tool }\end{array}$ & University of Oregon & \begin{tabular}{|l|} 
cinnamide-based \\
NMDA antagonists, \\
CoCensys
\end{tabular} & $\begin{array}{l}\text { Ischemia; } \\
\text { Neurological disease; } \\
\text { Injury; Head injury }\end{array}$ & $\begin{array}{l}\text { NMDA receptor } \\
\text { antagonist }\end{array}$ & Neuroprotectant \\
\hline 124 & $* *$ Discovery & INSERM & ciproxifan & $\begin{array}{l}\text { Epilepsy; Alzheimers } \\
\text { disease; Dementia }\end{array}$ & Histamine $\mathrm{H} 3$ antagonist & $\begin{array}{l}\text { Anticonvulsant } \\
\text { agent }\end{array}$ \\
\hline 126 & Discovery & $\begin{array}{l}\text { Cogent Neuroscience } \\
\text { Inc }\end{array}$ & CNIC-568 & $\begin{array}{l}\text { Neurodegenerative } \\
\text { disease; } \\
\text { Cerebrovascular } \\
\text { ischemia }\end{array}$ & $\begin{array}{l}\text { Unspecified vector based } \\
\text { gene therapy }\end{array}$ & Neuroprotectant \\
\hline 128 & $\begin{array}{l}\text { No } \\
\text { Development } \\
\text { Reported } \\
\end{array}$ & $\begin{array}{l}\text { CeNeS } \\
\text { Pharmaceuticals Inc }\end{array}$ & CNS-2103 & $\begin{array}{l}\text { Neurodegenerative } \\
\text { disease }\end{array}$ & \begin{tabular}{|l|} 
Calcium channel blocker \\
\end{tabular} & Neuroprotectant \\
\hline 129 & \begin{tabular}{|l} 
No \\
Development \\
Reported \\
\end{tabular} & $\begin{array}{l}\text { CeNeS } \\
\text { Pharmaceuticals Inc }\end{array}$ & CNS-5065 & $\begin{array}{l}\text { Neurodegenerative } \\
\text { disease }\end{array}$ & $\begin{array}{l}\text { NMDA receptor } \\
\text { antagonist }\end{array}$ & Neuroprotectant \\
\hline 130 & Discontinued & $\begin{array}{l}\text { Ryan Pharmaceuticals } \\
\text { Inc }\end{array}$ & Coenzyme Q10; & $\begin{array}{l}\text { Cerebrovascular } \\
\text { ischemia }\end{array}$ & Apopotsis inhibitor & Neuroprotectant \\
\hline 131 & **Clinical & $\begin{array}{l}\text { ReGen Therapeutics } \\
\text { plc }\end{array}$ & Colostrinin & Alzheimers disease & $\begin{array}{l}\text { Amyloid protein } \\
\text { deposition inhibitor; } \\
\text { Proline rich peptide from } \\
\text { colostorinin }\end{array}$ & $\begin{array}{l}\text { Immunomodulator; } \\
\text { Antioxidant agent }\end{array}$ \\
\hline 134 & $* *$ Discovery & Pfizer Inc & CP-465022 & $\begin{array}{l}\text { Epilepsy; Parkinsons } \\
\text { disease; Ischemia }\end{array}$ & $\begin{array}{l}\text { AMPA receptor } \\
\text { antagonist }\end{array}$ & $\begin{array}{l}\text { Antiparkinsonian; } \\
\text { Anticonvulsant } \\
\text { agent }\end{array}$ \\
\hline 135 & $\begin{array}{l}\text { *No } \\
\text { Development } \\
\text { Reported } \\
\text { (Discovery) }\end{array}$ & $\begin{array}{l}\text { Questcor } \\
\text { Pharmaceuticals Inc }\end{array}$ & CPC-304 & $\begin{array}{l}\text { Neurodegenerative } \\
\text { disease; } \\
\text { Alzheimers disease; } \\
\text { Cerebrovascular } \\
\text { ischemia }\end{array}$ & \begin{tabular}{|l|} 
Calcium channel blocker \\
\end{tabular} & Neuroprotectant \\
\hline 136 & $\begin{array}{l}\text { Phase } 2 \\
\text { Clinical } \\
\end{array}$ & \begin{tabular}{|l|} 
Cortex \\
Pharmaceuticals Inc \\
\end{tabular} & CX-516 & $\begin{array}{l}\text { Cognitive disorder; } \\
\text { Alzheimers disease }\end{array}$ & $\begin{array}{l}\text { Ampa receptor } \\
\text { modulator }\end{array}$ & Neuroprotectant \\
\hline 137 & $\begin{array}{l}\text { Phase 1 } \\
\text { Clinical }\end{array}$ & NIMH & Cyclophosphamide & $\begin{array}{l}\text { Alzheimers disease; } \\
\text { Neurodegenerative } \\
\text { disease }\end{array}$ & $\begin{array}{l}\text { Immunomodulator; } \\
\text { Alkylating agent }\end{array}$ & $\begin{array}{l}\text { Neuroprotectant; } \\
\text { Anti-inflammatory }\end{array}$ \\
\hline 138 & Discovery & Maas Biolab LLC & Cyclosporin A & $\begin{array}{l}\text { Alzheimer disease; } \\
\text { Parkinsons disease; } \\
\text { ALS; Huntingtons } \\
\text { disease }\end{array}$ & $\begin{array}{l}\text { Immunomodulator; } \\
\text { Calcineurin inhibitor }\end{array}$ & $\begin{array}{l}\text { Neuroprotectant; } \\
\text { Anti-inflammatory }\end{array}$ \\
\hline 139 & Discontinued & Servier & Dabelotine & $\begin{array}{l}\text { Alzheimes disease; } \\
\text { Dementia }\end{array}$ & $\begin{array}{l}\text { Adrenoceptor agonist; } \\
\text { Vasopressin agonist }\end{array}$ & Nootropic agent \\
\hline
\end{tabular}




\begin{tabular}{|c|c|c|c|c|c|c|}
\hline & $\begin{array}{l}\text { Highest dev. } \\
\text { status }\end{array}$ & Company & Drug & Indication & Mode of action & Drug effect \\
\hline 140 & **Discovery & DarPharma Inc & DAR-201 & \begin{tabular}{|l|} 
Parkinsons disease; \\
Schizophrenia; \\
Attention deficit \\
hyperactivity disorder
\end{tabular} & Dopamine D1 agonist & $\begin{array}{l}\text { Antipsychotic; } \\
\text { Antiparkinsonian }\end{array}$ \\
\hline 141 & Research Tool & Suntory Ltd & DCG-IV & $\begin{array}{l}\text { Neurodegenerative } \\
\text { disease }\end{array}$ & $\begin{array}{l}\text { Glutamate receptor } \\
\text { agonist at mGlu-R group } \\
\text { II receptors; Antagonist } \\
\text { at mGlu-R group III } \\
\text { receptors }\end{array}$ & Neuroprotectant \\
\hline 142 & Discovery & DiverDrugsSL & DD-20207 & $\begin{array}{l}\text { Alzheimers disease; } \\
\text { Parkinsons disease }\end{array}$ & $\begin{array}{l}\text { NMDA receptor } \\
\text { modulator }\end{array}$ & $\begin{array}{l}\text { Analgesic, } \\
\text { Antiparkinsonian }\end{array}$ \\
\hline 143 & Discovery & $\begin{array}{l}\text { Memorial Sloan- } \\
\text { Kettering Cancer } \\
\text { Center }\end{array}$ & $\begin{array}{l}\text { Dehydroascorbic } \\
\text { acid }\end{array}$ & $\begin{array}{l}\text { Alzheimers disease; } \\
\text { Neurodegenerative } \\
\text { disease; Parkinsons } \\
\text { disease; } \\
\text { Cerebrovascular } \\
\text { ischemia }\end{array}$ & Antioxidant agent & $\begin{array}{l}\text { Neuroprotectant; } \\
\text { Anti-inflammatory }\end{array}$ \\
\hline 144 & $\begin{array}{l}* * \text { Phase } 1 \\
\text { Clinical }\end{array}$ & $\begin{array}{l}\text { NPS Pharmaceuticals } \\
\text { Inc }\end{array}$ & $\begin{array}{l}\text { delucemine, NPS } \\
1506\end{array}$ & $\begin{array}{l}\text { Cerebrovascular } \\
\text { ischemia; Major } \\
\text { depressive disorder }\end{array}$ & $\begin{array}{l}\text { NMDA open channel } \\
\text { blocker }\end{array}$ & $\begin{array}{l}\text { Neuroprotectant; } \\
\text { Antidepressant }\end{array}$ \\
\hline 145 & Discontinued & Hebrew University & dexanabinol & $\begin{array}{l}\text { Cognitive disorder, } \\
\text { Brain injury }\end{array}$ & $\begin{array}{l}\text { NMDA receptor } \\
\text { antagonist; TNF- } \alpha \\
\text { inhibitor; Free radical } \\
\text { scavenger }\end{array}$ & Neuroprotectant \\
\hline 146 & $\begin{array}{l}\text { Phase 1 } \\
\text { Clinical }\end{array}$ & $\begin{array}{l}\text { Pierre Fabre SA / } \\
\text { Reckitt \& Colman plc }\end{array}$ & Dexefaroxan & Alzheimers disease & $\begin{array}{l}\text { Imidazoline receptor } \\
\text { antagonist, Alpha } 2 \\
\text { adrenoceptor antagonist }\end{array}$ & Neuroprotectant \\
\hline 147 & $\begin{array}{l}* * \text { Phase } 2 \\
\text { Clinical }\end{array}$ & $\begin{array}{l}\text { Purdue Research } \\
\text { Foundation }\end{array}$ & dihydrexidine & $\begin{array}{l}\text { Parkinsons disease; } \\
\text { Schizophrenia }\end{array}$ & Dopamine D1 agonist & Antiparkinsonian \\
\hline 148 & Discovery & Schering AG & Dihydroquinolines & $\begin{array}{l}\text { Neurodegenerative } \\
\text { disease }\end{array}$ & NO synthesis inhibitor & Neuroprotectant \\
\hline 149 & $\begin{array}{l}\text { No } \\
\text { Development } \\
\text { Reported }\end{array}$ & SIR International & Diperdipine & $\begin{array}{l}\text { Neurodegenerative } \\
\text { disease; Cerebral } \\
\text { infarction; } \\
\text { Cerebrovascular } \\
\text { disease; } \\
\text { Cerebrovascular } \\
\text { ischemia }\end{array}$ & Calcium channel blocker & Antihypertensive \\
\hline 150 & Research Tool & Merck \& Co Inc & dizocilpine & $\begin{array}{l}\text { Epilepsy; } \\
\text { Neurodegenerative } \\
\text { disease; Cognitive } \\
\text { disorder } \\
\end{array}$ & NMDA channel blocker & $\begin{array}{l}\text { Anticonvulsant } \\
\text { agent }\end{array}$ \\
\hline 151 & Discontinued & $\begin{array}{l}\text { Bristol-Myers Squibb } \\
\text { Co }\end{array}$ & DMP-543 & Alzheimers disease & $\begin{array}{l}\text { Potassium channel } \\
\text { blocker }\end{array}$ & Neuroprotectant \\
\hline 152 & **Discovery & $\begin{array}{l}\text { Novasite } \\
\text { Pharmaceuticals Inc }\end{array}$ & $\begin{array}{l}\text { dopamine D1 } \\
\text { receptor agonists } \\
\text { (schizophrenia), } \\
\text { Novasite } \\
\end{array}$ & $\begin{array}{l}\text { Parkinsons disease; } \\
\text { Schizophrenia }\end{array}$ & Dopamine D1 agonist & Antiparkinsonian \\
\hline 153 & **Discovery & $\begin{array}{l}\text { SmithKline Beecham } \\
\text { plc }\end{array}$ & $\begin{array}{l}\text { dopamine D3 } \\
\text { antagonists, } \\
\text { GlaxoSmithKline }\end{array}$ & $\begin{array}{l}\text { Psychosis; } \\
\text { Schizophrenia; } \\
\text { Cocaine addiction } \\
\end{array}$ & Dopamine D3 antagonist & Antipsychotic \\
\hline
\end{tabular}




\begin{tabular}{|c|c|c|c|c|c|c|}
\hline & $\begin{array}{l}\text { Highest dev. } \\
\text { status }\end{array}$ & Company & Drug & Indication & Mode of action & Drug effect \\
\hline 154 & $* *$ Discovery & $\begin{array}{l}\text { Memory } \\
\text { Pharmaceuticals Corp }\end{array}$ & $\begin{array}{l}\text { dopamine } \\
\text { D5 receptor } \\
\text { modulators, } \\
\text { Memory }\end{array}$ & Parkinsons disease & $\begin{array}{l}\text { Dopamine D5 receptor } \\
\text { modulator }\end{array}$ & Antiparkinsonian \\
\hline 155 & **Discovery & Organix Inc & $\begin{array}{l}\text { dopamine } \\
\text { transporter ligand, } \\
\text { Organix }\end{array}$ & $\begin{array}{l}\text { Parkinsons disease; } \\
\text { Schizophrenia; } \\
\text { Cocaine addiction }\end{array}$ & $\begin{array}{l}\text { Dopamine transporter } \\
\text { inhibitor }\end{array}$ & $\begin{array}{l}\text { Antipsychotic; } \\
\text { Antiparkinsonian }\end{array}$ \\
\hline 156 & Discovery & D-Pharm Ltd & DP-103 & $\begin{array}{l}\text { Nervous system } \\
\text { inflammation }\end{array}$ & & Anti-inflammatory \\
\hline 157 & Discovery & D-Pharm Ltd & DP-109 & $\begin{array}{l}\text { Neurodegenerative } \\
\text { disease }\end{array}$ & $\begin{array}{l}\text { Chelating agent; } \\
\text { Apoptosis modulator }\end{array}$ & Neuroprotectant \\
\hline 158 & $\begin{array}{l}* \text { Phase } 2 \\
\text { Clinical } \\
\text { (Discovery) }\end{array}$ & D-Pharm Ltd & DP-b99 & $\begin{array}{l}\text { Cerebrovascular } \\
\text { ischemia, Epilepsy }\end{array}$ & $\begin{array}{l}\text { Chelating agent, Calcium } \\
\text { metabolism modulator }\end{array}$ & $\begin{array}{l}\text { Neuroprotectant, } \\
\text { Anticonvulsant } \\
\text { agent }\end{array}$ \\
\hline 160 & **Discovery & $\begin{array}{l}\text { Meiji Seika Kaisha } \\
\text { Ltd }\end{array}$ & DR-2313 & $\begin{array}{l}\text { Cerebrovascular } \\
\text { ischemia }\end{array}$ & PARP inhibitor & Neuroprotectant \\
\hline 161 & $\begin{array}{l}* * \text { Phase } 1 \\
\text { Clinical }\end{array}$ & $\begin{array}{l}\text { Daiichi Seiyaku Co } \\
\text { Ltd }\end{array}$ & DY-9760e & $\begin{array}{l}\text { Cerebrovascular } \\
\text { ischemia; } \\
\text { Neurological disease }\end{array}$ & Calmodulin antagonist & $\begin{array}{l}\text { Neuroprotectant; } \\
\text { Protectant }\end{array}$ \\
\hline 162 & Discovery & \begin{tabular}{|l|} 
Korea Research \\
Institute of Bioscience \\
and Biotechnology
\end{tabular} & Dykellic acid & $\begin{array}{l}\text { Immune disorder; } \\
\text { Neurodegenerative } \\
\text { disease; Cancer }\end{array}$ & MMP-5 inhibitor & $\begin{array}{l}\text { Anticancer; Anti- } \\
\text { apoptotic }\end{array}$ \\
\hline 163 & $\begin{array}{l}* * \text { Phase } 2 \\
\text { Clinical }\end{array}$ & Eisai Co Ltd & E-2007 & $\begin{array}{l}\text { Epilepsy; Multiple } \\
\text { sclerosis; Parkinsons } \\
\text { disease }\end{array}$ & $\begin{array}{l}\text { AMPA receptor } \\
\text { antagonist; } \\
\text { Anticonvulsant agent }\end{array}$ & Neuroprotectant \\
\hline 167 & Discontinued & $\begin{array}{l}\text { BTG International } \\
\text { Ltd; Novartis }\end{array}$ & $\begin{array}{l}\text { EAA-494; } \\
\text { Midafotel }\end{array}$ & $\begin{array}{l}\text { Epilepsy; } \\
\text { Neurodegenerative } \\
\text { disease; } \\
\text { Cerebrovascular } \\
\text { ischemia; Head injury }\end{array}$ & $\begin{array}{l}\text { NMDA receptor } \\
\text { antagonist }\end{array}$ & Neuroprotectant \\
\hline 168 & Discovery & Wyeth Research & EAB-318 & $\begin{array}{l}\text { Epilepsy; } \\
\text { Neurodegenerative } \\
\text { disease; } \\
\text { Cerebrovascular } \\
\text { ischemia }\end{array}$ & $\begin{array}{l}\text { NMDA receptor } \\
\text { antagonist }\end{array}$ & $\begin{array}{l}\text { Neuroprotectant; } \\
\text { Anticonvulsant } \\
\text { agent }\end{array}$ \\
\hline 169 & $* *$ Discovery & NsGene A/S & ECT-AD & $\begin{array}{l}\text { Alzheimers disease; } \\
\text { Neurological disease }\end{array}$ & NGF agonist & $\begin{array}{l}\text { Neuroprotectant; } \\
\text { Growth factor }\end{array}$ \\
\hline 170 & **Discovery & NsGene A/S & ECT-PD & Parkinsons disease & $\begin{array}{l}\text { Neuronal growth factor } \\
\text { receptor agonist }\end{array}$ & $\begin{array}{l}\text { Neuroprotectant; } \\
\text { Growth factor }\end{array}$ \\
\hline
\end{tabular}




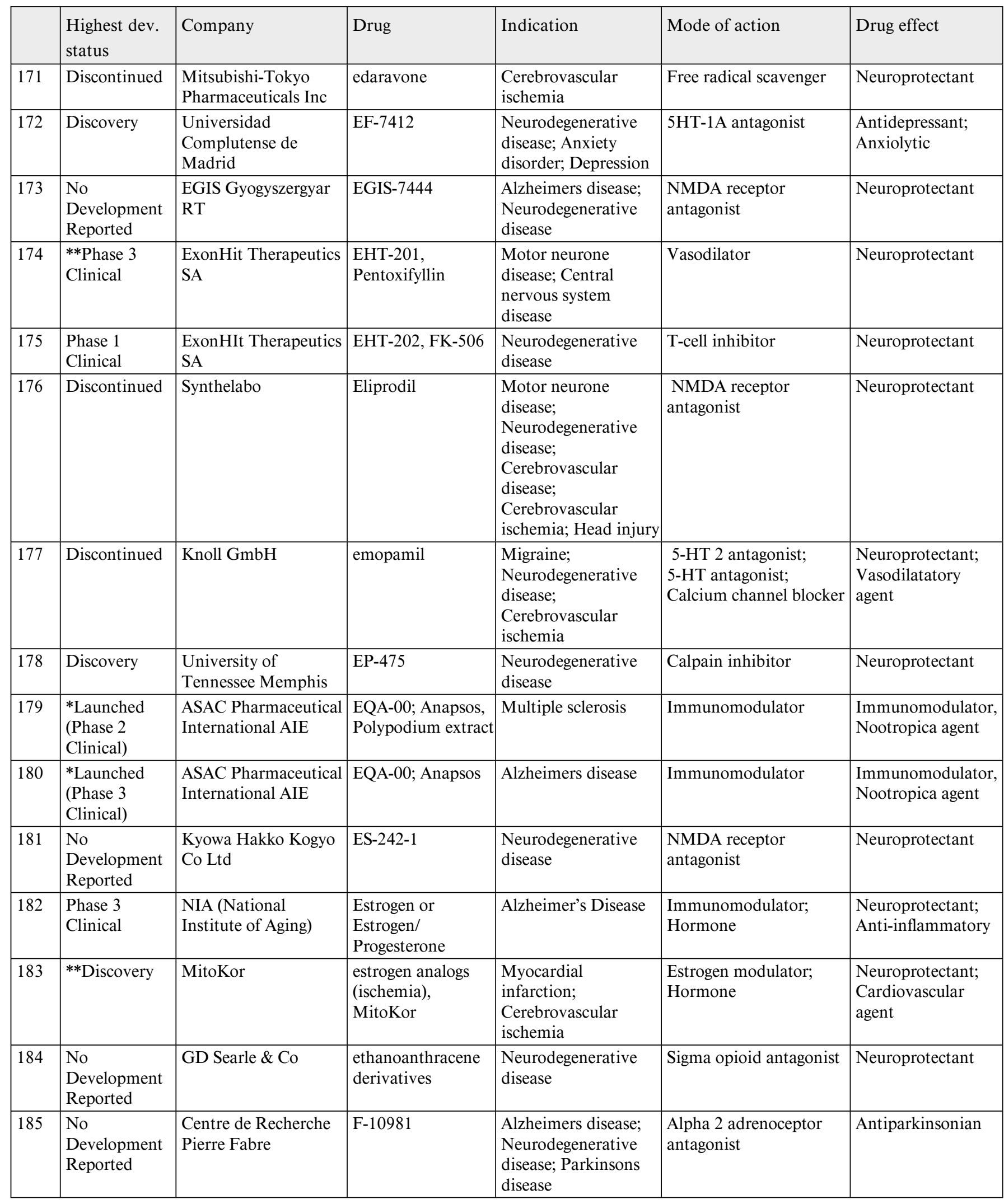




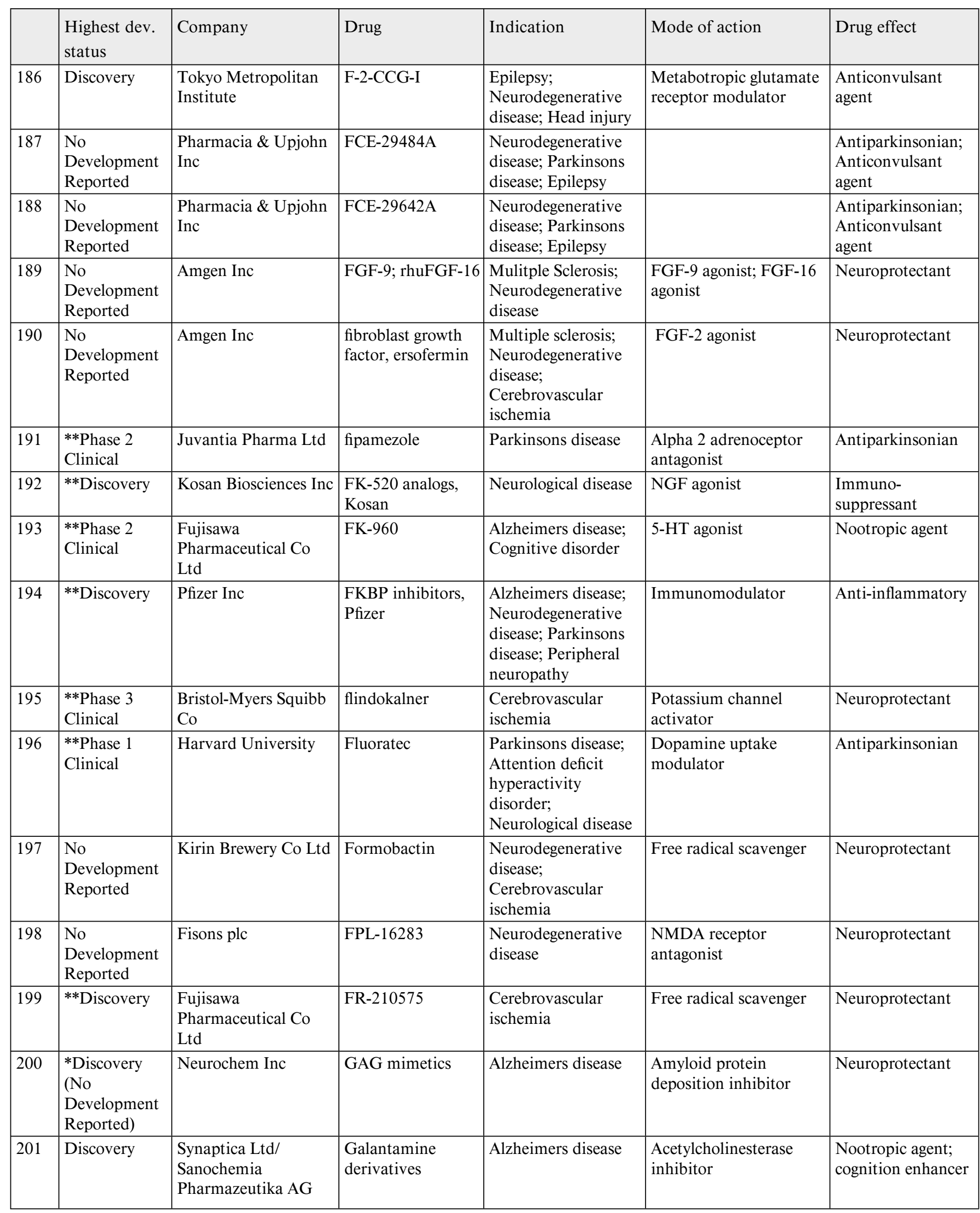




\begin{tabular}{|c|c|c|c|c|c|c|}
\hline & $\begin{array}{l}\text { Highest dev. } \\
\text { status }\end{array}$ & Company & Drug & Indication & Mode of action & Drug effect \\
\hline 202 & \begin{tabular}{|l|} 
No \\
Development \\
Reported \\
\end{tabular} & GlaxoSmithKline plc & galdansetron & $\begin{array}{l}\text { Neurodegenerative } \\
\text { disease }\end{array}$ & 5-HT 3 antagonist & Neuroprotectant \\
\hline 203 & $* *$ Discovery & $\begin{array}{l}\text { Elan Pharmaceuticals } \\
\text { Inc }\end{array}$ & $\begin{array}{l}\text { gamma-secretase } \\
\text { inhibitors, Elan/ } \\
\text { Lilly }\end{array}$ & Alzheimers disease & $\begin{array}{l}\text { Beta amyloid synthesis } \\
\text { inhibitor; Gamma- } \\
\text { secretase inhibitor; } \\
\text { Aspartic protease } \\
\text { inhibitor }\end{array}$ & Neuroprotectant \\
\hline 204 & $\begin{array}{l}\text { Phase } 2 \\
\text { Clinical }\end{array}$ & $\begin{array}{l}\text { Chiesi Farmaceutici } \\
\text { SpA }\end{array}$ & ganstigmine & $\begin{array}{l}\text { Alzheimers disease; } \\
\text { Neurodegenerative } \\
\text { disease; Cognitive } \\
\text { disorder }\end{array}$ & $\begin{array}{l}\text { Acetylcholinesterase } \\
\text { inhibitor }\end{array}$ & Neuroprotectant \\
\hline 206 & Discovery & Genentech Inc & GDNF & $\begin{array}{l}\text { Neurodegenerative } \\
\text { disease; Parkinsons } \\
\text { disease }\end{array}$ & $\begin{array}{l}\text { Unspecific growth factor } \\
\text { agonist }\end{array}$ & Antiparkinsonian \\
\hline 207 & $\begin{array}{l}\text { Phase } 2 \\
\text { Clinical }\end{array}$ & Amgen Inc & $\begin{array}{l}\text { GDNF; } \\
\text { Liatermine }\end{array}$ & $\begin{array}{l}\text { Motor neurone } \\
\text { disease; } \\
\text { Neurodegenerative } \\
\text { disease; Parkinsons } \\
\text { disease }\end{array}$ & Growth factor & Antiparkinsonian \\
\hline 208 & **Discovery & Oxford BioMedica plc & $\begin{array}{l}\text { gene therapy } \\
\text { (ALS), Oxford } \\
\text { BioMedica }\end{array}$ & $\begin{array}{l}\text { Motor neurone } \\
\text { disease }\end{array}$ & $\begin{array}{l}\text { Viral vector based gene } \\
\text { therapy }\end{array}$ & Neuroprotectant \\
\hline 211 & $\begin{array}{l}\text { Phase } 2 \\
\text { Clinical }\end{array}$ & $\begin{array}{l}\text { ViatraVIATRIS } \\
\text { GmbH }\end{array}$ & $\begin{array}{l}\text { GKE-841; } \\
\text { retigabine }\end{array}$ & Epilepsy & $\begin{array}{l}\text { GABA A agonist; } \\
\text { Potassium channel } \\
\text { activator }\end{array}$ & $\begin{array}{l}\text { Anticonvulsant } \\
\text { agent }\end{array}$ \\
\hline 212 & \begin{tabular}{|l} 
No \\
Development \\
Reported \\
\end{tabular} & $\begin{array}{l}\text { Allelix Neuroscience } \\
\text { Inc }\end{array}$ & $\begin{array}{l}\text { Glialines, } \\
\text { Throphix }\end{array}$ & $\begin{array}{l}\text { Alzheimers disease; } \\
\text { Huntingtons chorea; } \\
\text { Parkinsons disease }\end{array}$ & $\begin{array}{l}\text { Cell therapy; Glial } \\
\text { neurotrophic factors }\end{array}$ & $\begin{array}{l}\text { Neuroprotectant; } \\
\text { Antiparkinsonian }\end{array}$ \\
\hline 213 & **Discovery & Glaxo Wellcome SpA & $\begin{array}{l}\text { glycine } \\
\text { antagonists, } \\
\text { GlaxoSmithKline }\end{array}$ & $\begin{array}{l}\text { Epilepsy; Pain; } \\
\text { Schizophrenia; } \\
\text { Cerebrovascular } \\
\text { ischemia; Head } \\
\text { injury } \\
\end{array}$ & $\begin{array}{l}\text { Glycine antagonist; } \\
\text { NMDA receptor } \\
\text { antagonist; } \\
\text { Anticonvulsant agent }\end{array}$ & $\begin{array}{l}\text { Neuroprotectant; } \\
\text { Antipsychotic; } \\
\text { Analgesic; }\end{array}$ \\
\hline 214 & **Discovery & Eli Lilly \& Co & $\begin{array}{l}\text { glycine transporter } \\
\text { inhibitors, Lilly }\end{array}$ & Schizophrenia & $\begin{array}{l}\text { Glycine transport } \\
\text { inhibitor }\end{array}$ & Antipsychotic \\
\hline 215 & $* *$ Discovery & $\begin{array}{l}\text { Allelix Neuroscience } \\
\text { Inc }\end{array}$ & $\begin{array}{l}\text { GlyT-1 inhibitors, } \\
\text { NPS/Janssen }\end{array}$ & $\begin{array}{l}\text { Schizophrenia; } \\
\text { Dementia }\end{array}$ & Glycine modulator & Antipsychotic \\
\hline
\end{tabular}




\begin{tabular}{|c|c|c|c|c|c|c|}
\hline & $\begin{array}{l}\text { Highest dev. } \\
\text { status }\end{array}$ & Company & Drug & Indication & Mode of action & Drug effect \\
\hline 216 & $\begin{array}{l}* \text { Clinical } \\
\text { (Enrollment) }\end{array}$ & $\begin{array}{l}\text { NINDS (National } \\
\text { Institute of } \\
\text { Neurological } \\
\text { Disorders and Stroke) }\end{array}$ & GM-1 ganglioside & $\begin{array}{l}\text { Neurodegenerative } \\
\text { disease }\end{array}$ & Unclear mechanism & Neuroprotectant \\
\hline 217 & $\begin{array}{l}\text { Phase 2 } \\
\text { Clinical }\end{array}$ & Fidia Farmaceutici & GM-1 ganglioside & Parkinsons disease & Unclear mechanism & Neuroprotectant \\
\hline 219 & $\begin{array}{l}\text { No } \\
\text { Development } \\
\text { Reported }\end{array}$ & SICOR Inc & GP-14683 & $\begin{array}{l}\text { Epilepsy; Angina; } \\
\text { Neurodegenerative } \\
\text { disease }\end{array}$ & ARA-100 prodrug & $\begin{array}{l}\text { Vasodilatatory } \\
\text { agent; } \\
\text { Anticonvulsant } \\
\text { agent }\end{array}$ \\
\hline 222 & Research Tool & GlaxoSmithKline plc & GR-73632 & $\begin{array}{l}\text { Neurodegenerative } \\
\text { disease }\end{array}$ & NK1 agonist & Neuroprotectant \\
\hline 223 & Discontinued & GlaxoSmithKline plc & GR-89696 & $\begin{array}{l}\text { Neurodegenerative } \\
\text { disease }\end{array}$ & Kappa opioid agonist & Neuroprotectant \\
\hline 224 & Discovery & AstraZeneca plc & GSK-3 inhibitors & Alzheimers disease & $\begin{array}{l}\text { Gylcogen synthase } \\
\text { kinase family inhibitor }\end{array}$ & Neuroprotectant \\
\hline 225 & Discontinued & Gliatech Inc & GT-2342 & $\begin{array}{l}\text { Neurodegenerative } \\
\text { disease }\end{array}$ & Histamine H3-ligand & Neuroprotectant \\
\hline 228 & Discontinued & $\begin{array}{l}\text { EGIS Gyogyszergyar } \\
\text { RT }\end{array}$ & GYKI-52466 & $\begin{array}{l}\text { Alzheimers disease; } \\
\text { Parkinsons disease; } \\
\text { Epilepsy }\end{array}$ & $\begin{array}{l}\text { AMPA receptor } \\
\text { antagonist }\end{array}$ & $\begin{array}{l}\text { Anticonvulsant } \\
\text { agent, } \\
\text { Antiparkinsonian }\end{array}$ \\
\hline 229 & $\begin{array}{l}\text { No } \\
\text { Development } \\
\text { Reported }\end{array}$ & $\begin{array}{l}\text { American Cyanamid } \\
\text { Co }\end{array}$ & HBNF & $\begin{array}{l}\text { Hematological } \\
\text { disease; } \\
\text { Neurodegenerative } \\
\text { disease }\end{array}$ & $\begin{array}{l}\text { Heparin binding } \\
\text { neurotrophic factor; } \\
\text { FGF-8 agonist, Peptide }\end{array}$ & \\
\hline 230 & Discovery & Hunter-Fleming Ltd & HF-0220 & $\begin{array}{l}\text { Cerebrovascular } \\
\text { ischemia }\end{array}$ & $\begin{array}{l}\text { 7-hydroxysteroid } \\
\text { pathway modulater }\end{array}$ & Neuroprotectant \\
\hline 231 & **Discovery & Curis Inc & Hh agonists, Curis & $\begin{array}{l}\text { Diabetic neuropathy; } \\
\text { Infertility; Alopecia; } \\
\text { Parkinsons disease; } \\
\text { Bone disease; } \\
\text { Neurological disease }\end{array}$ & Hedgehog agonist & $\begin{array}{l}\text { Neuroprotectant; } \\
\text { Antiparkinsonian }\end{array}$ \\
\hline 232 & $\begin{array}{l}\text { *Phase } 2 \\
\text { Clinical } \\
\text { (Phase 1 } \\
\text { Clinical) }\end{array}$ & Aventis & HP-184 & Spinal chord injury & $\begin{array}{l}\text { Ion channel modulator, } \\
\text { Acetylcholine release } \\
\text { stimulator }\end{array}$ & Neuroprotectant \\
\hline
\end{tabular}




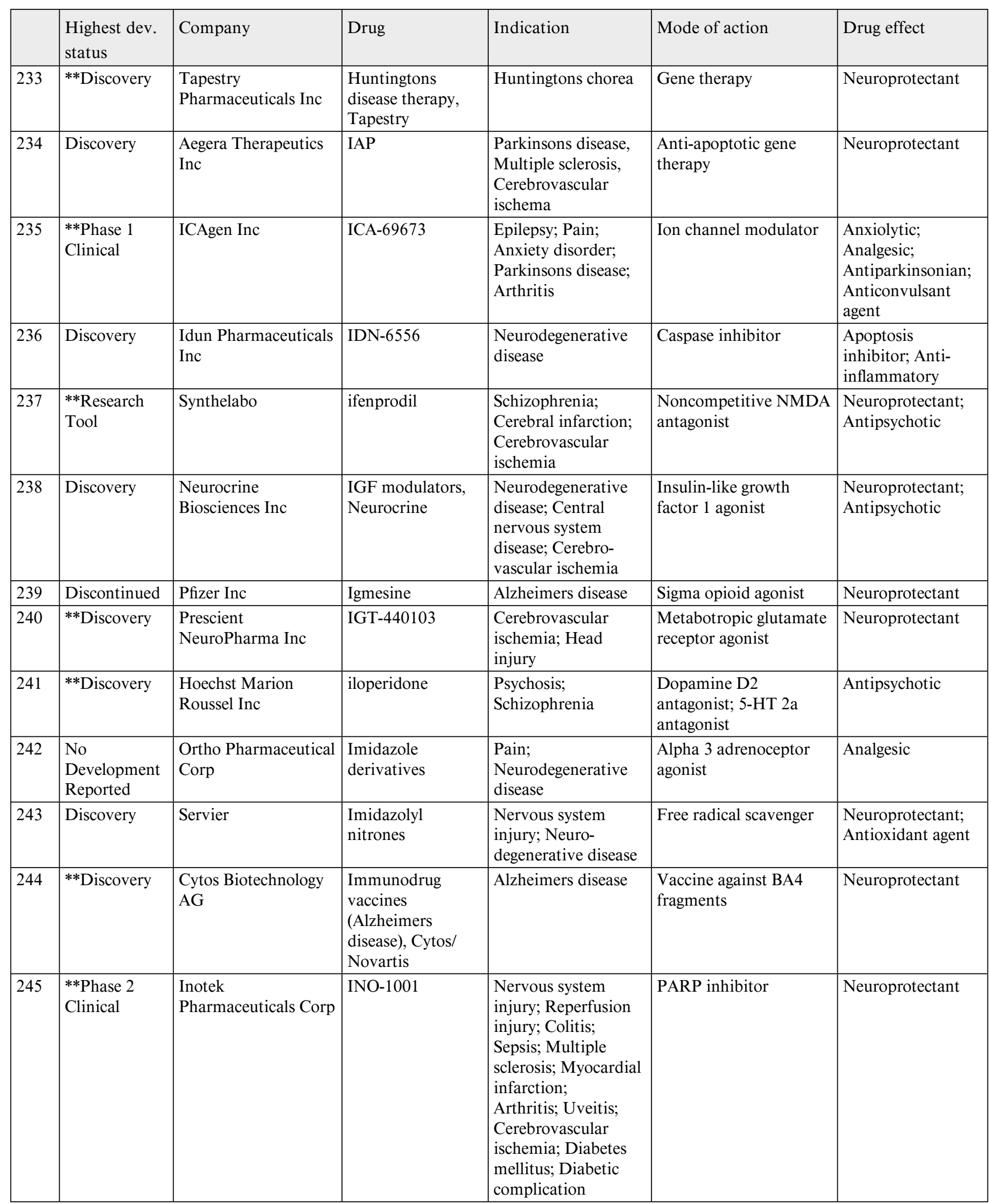




\begin{tabular}{|c|c|c|c|c|c|c|}
\hline 246 & Discovery & $\begin{array}{l}\text { Boston Life Sciences } \\
\text { Inc }\end{array}$ & inosine, BLSI & $\begin{array}{l}\text { Neurodegenerative } \\
\text { disease }\end{array}$ & Adenosine precursor & Neuroprotectant \\
\hline 247 & $\begin{array}{l}\text { Phase } 1 \text { - } 2 \\
\text { Clinical }\end{array}$ & NCRR & Interferon Alpha & $\begin{array}{l}\text { Alzheimers disease; } \\
\text { Dementia }\end{array}$ & Immunomodulator & $\begin{array}{l}\text { Neuroprotectant; } \\
\text { Anti-inflammatory }\end{array}$ \\
\hline 248 & \begin{tabular}{|l} 
No \\
Development \\
Reported \\
\end{tabular} & $\begin{array}{l}\text { Yeda Research \& } \\
\text { Development Co Ltd }\end{array}$ & $\begin{array}{l}\text { Interleukin-2-like } \\
\text { growth factor }\end{array}$ & $\begin{array}{l}\text { Neurodegenerative } \\
\text { disease }\end{array}$ & IL-2 agonist & $\begin{array}{l}\text { Growth factor } \\
\text { agonist }\end{array}$ \\
\hline 249 & \begin{tabular}{|l|} 
*Pre- \\
registration \\
(Phase 3 \\
Clinical)
\end{tabular} & $\begin{array}{l}\text { Research Triangle } \\
\text { Institute }\end{array}$ & Iometopane & Parkinsons disease & $\begin{array}{l}\text { Dopamine uptake } \\
\text { inhibitor; SPECT } \\
\text { contrast agent }\end{array}$ & $\begin{array}{l}\text { Neuroprotectant; } \\
\text { Antiparkinsonian }\end{array}$ \\
\hline 250 & $\begin{array}{l}\text { Phase } 2 \\
\text { Clinical }\end{array}$ & $\begin{array}{l}\text { Nippon Chemiphar } \\
\text { Co Ltd }\end{array}$ & Ipenoxazone & $\begin{array}{l}\text { Alzheimers disease; } \\
\text { Neurodegenerative } \\
\text { disease; Middle ear } \\
\text { disease }\end{array}$ & $\begin{array}{l}\text { NMDA receptor } \\
\text { antagonist; Ionotropic } \\
\text { glutamate receptor } \\
\text { antagonist }\end{array}$ & $\begin{array}{l}\text { Smooth muscle } \\
\text { relaxantium }\end{array}$ \\
\hline 251 & Discovery & Chronogen Inc & isp-1; clk-1 & $\begin{array}{l}\text { Neurodegenerative } \\
\text { disease }\end{array}$ & $\begin{array}{l}\text { Protein tyrosine kinase } \\
\text { STY }\end{array}$ & Neuroprotectant \\
\hline 252 & $\begin{array}{l}* * \text { Phase } 2 \\
\text { Clinical }\end{array}$ & $\begin{array}{l}\text { Kyowa Hakko Kogyo } \\
\text { Co Ltd }\end{array}$ & istradefylline & $\begin{array}{l}\text { Parkinsons disease; } \\
\text { Major depressive } \\
\text { disorder }\end{array}$ & $\begin{array}{l}\text { Adenosine A2a } \\
\text { antagonist }\end{array}$ & $\begin{array}{l}\text { Antidepressant; } \\
\text { Antiparkinsonian }\end{array}$ \\
\hline 253 & $* *$ Discovery & $\begin{array}{l}\text { Bristol-Myers Squibb } \\
\text { Pharma Co }\end{array}$ & IT-657 & Schizophrenia & $\begin{array}{l}\text { Dopamine D2 } \\
\text { antagonist; 5-HT 2a } \\
\text { antagonist }\end{array}$ & Antipsychotic \\
\hline 254 & $\begin{array}{l}\text { No } \\
\text { Development } \\
\text { Reported }\end{array}$ & Aventis & itameline & $\begin{array}{l}\text { Dementia, } \\
\text { Alzheimers disease, } \\
\text { Cognitive disorder }\end{array}$ & Muscarinic ACh agonist & Nootropic agent \\
\hline 256 & $\begin{array}{l}\text { No } \\
\text { Development } \\
\text { Reported }\end{array}$ & $\begin{array}{l}\text { Kyowa Hakko Kogyo } \\
\text { Co Ltd }\end{array}$ & KF-17329 & $\begin{array}{l}\text { Neurodegenerative } \\
\text { disease; } \\
\text { Cerebrovascular } \\
\text { ischemia }\end{array}$ & & Neuroprotectant \\
\hline 257 & $\begin{array}{l}* \text { Dis- } \\
\text { continued }\end{array}$ & $\begin{array}{l}\text { Krenitsky } \\
\text { Pharmeceuticals Inc }\end{array}$ & KP-102 & $\begin{array}{l}\text { Neurodegenerative } \\
\text { disease }\end{array}$ & NGF agonist & Neurotrophic agent \\
\hline 258 & $* *$ Discovery & $\begin{array}{l}\text { Kyorin } \\
\text { Pharmaceutical Co } \\
\text { Ltd }\end{array}$ & KRP-199 & $\begin{array}{l}\text { Cerebrovascular } \\
\text { ischemia }\end{array}$ & $\begin{array}{l}\text { AMPA receptor } \\
\text { antagonist }\end{array}$ & Neuroprotectant \\
\hline 259 & Discovery & $\begin{array}{l}\text { Keryx } \\
\text { Biopharmaceuticals } \\
\text { Inc }\end{array}$ & KRX-411 & $\begin{array}{l}\text { Neurodegenerative } \\
\text { disease }\end{array}$ & $\begin{array}{l}\text { Protein kinase } \\
\text { modulator }\end{array}$ & Neuroprotectant \\
\hline
\end{tabular}




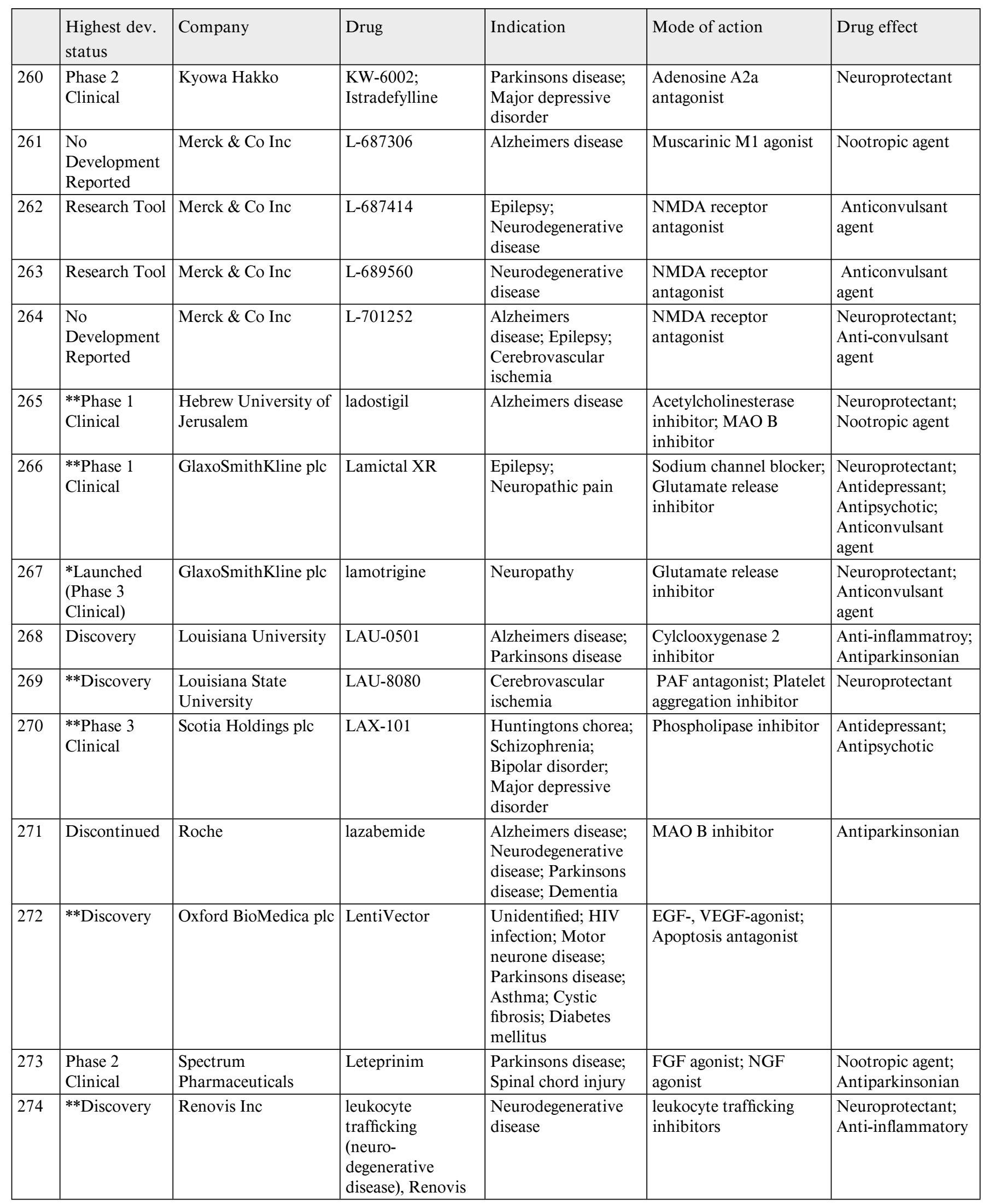




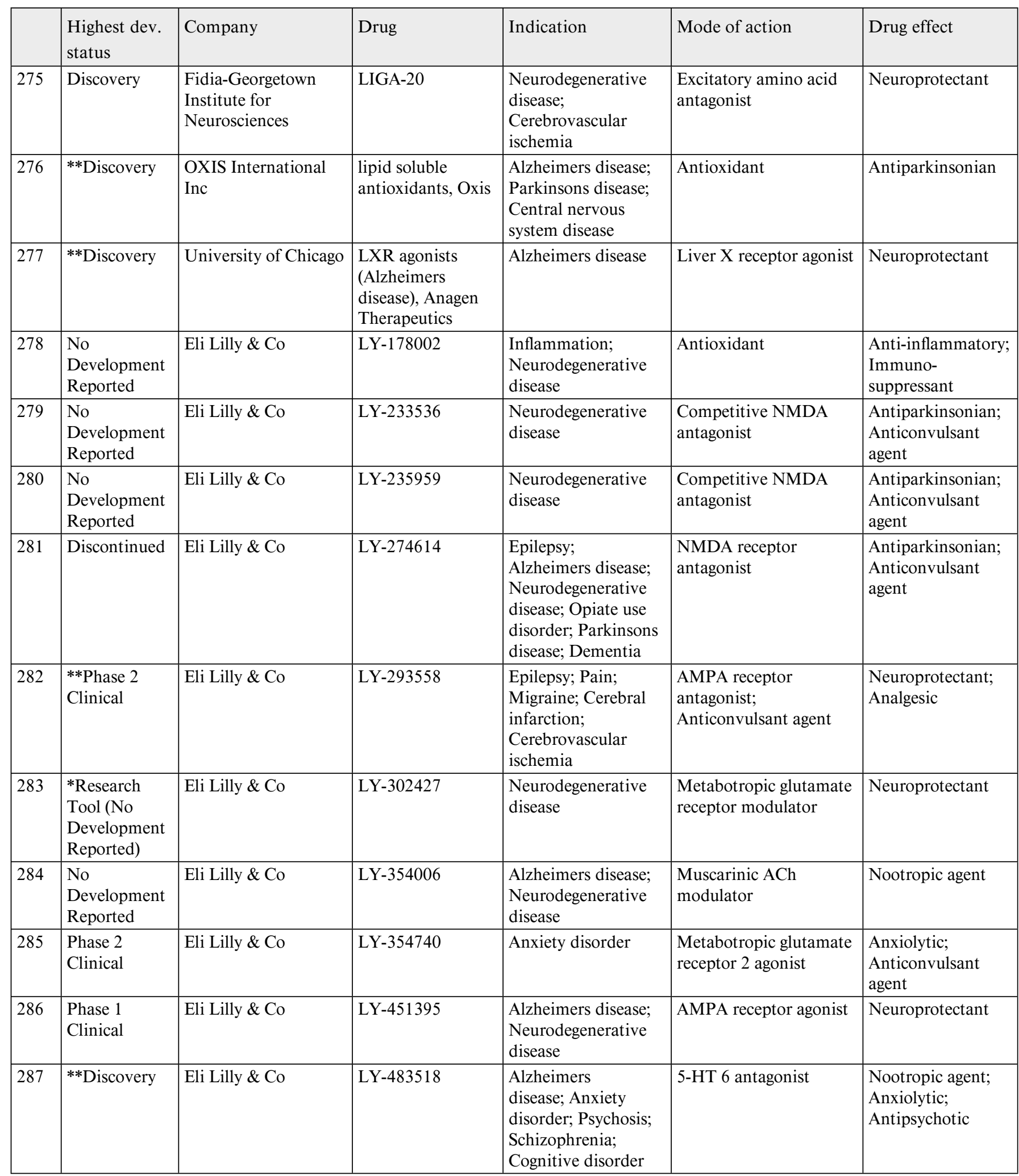




\begin{tabular}{|c|c|c|c|c|c|c|}
\hline & $\begin{array}{l}\text { Highest dev. } \\
\text { status }\end{array}$ & Company & Drug & Indication & Mode of action & Drug effect \\
\hline 288 & **Discovery & $\begin{array}{l}\text { MetaPhore } \\
\text { Pharmaceuticals Inc }\end{array}$ & M-40401 & $\begin{array}{l}\text { Reperfusion injury; } \\
\text { HIV infection; } \\
\text { Parkinsons disease; } \\
\text { Shock; Encephalitis }\end{array}$ & $\begin{array}{l}\text { Viral replication } \\
\text { inhibitor; Apoptosis } \\
\text { inhibitor; Superoxide } \\
\text { dismutase stimulator; } \\
\text { HIV replication } \\
\text { inhibitor }\end{array}$ & \\
\hline 289 & Discovery & $\begin{array}{l}\text { Mitsubishi-Tokyo } \\
\text { Pharmaceuticals Inc }\end{array}$ & MCC-257 & $\begin{array}{l}\text { Diabetic neuropathy; } \\
\text { Neurodegenerative } \\
\text { disease }\end{array}$ & NGF agonist & Neuroprotectant \\
\hline 290 & Discontinued & $\begin{array}{l}\text { Mitsubishi-Tokyo } \\
\text { Pharmaceuticals Inc }\end{array}$ & MCI-225 & $\begin{array}{l}\text { Alzheimers disease; } \\
\text { Neurodegenerative } \\
\text { disease; Depression }\end{array}$ & $\begin{array}{l}\text { 5-HT } 3 \text { antagonist; } \\
\text { Norepinephrine uptake } \\
\text { inhibitor }\end{array}$ & $\begin{array}{l}\text { Antidepressant; } \\
\text { Metabolic activator }\end{array}$ \\
\hline 291 & \begin{tabular}{|l|} 
No \\
Development \\
Reported \\
\end{tabular} & $\begin{array}{l}\text { Hoechst Marion } \\
\text { Roussel Inc }\end{array}$ & MDL-100748 & $\begin{array}{l}\text { Epilepsy; } \\
\text { Neurodegenerative } \\
\text { disease }\end{array}$ & $\begin{array}{l}\text { NMDA/Glycine } \\
\text { antagonist; Glycine } \\
\text { antagonist }\end{array}$ & $\begin{array}{l}\text { Anticonvulsant } \\
\text { agent }\end{array}$ \\
\hline 292 & Discontinued & $\begin{array}{l}\text { Hoechst Marion } \\
\text { Roussel Inc }\end{array}$ & MDL-101002 & $\begin{array}{l}\text { Neurodegenerative } \\
\text { disease; } \\
\text { Cerebrovascular } \\
\text { ischemia; Septic } \\
\text { shock }\end{array}$ & Free radical scavenger & $\begin{array}{l}\text { Neuroprotectant; } \\
\text { Antioxidant agent }\end{array}$ \\
\hline 293 & \begin{tabular}{|l|} 
No \\
Development \\
Reported \\
\end{tabular} & $\begin{array}{l}\text { Hoechst Marion } \\
\text { Roussel Inc }\end{array}$ & MDL-102288 & $\begin{array}{l}\text { Neurodegenerative } \\
\text { disease }\end{array}$ & Gylcine antagonist & Neuroprotectant \\
\hline 294 & \begin{tabular}{|l|} 
No \\
Development \\
Reported \\
\end{tabular} & $\begin{array}{l}\text { Hoechst Marion } \\
\text { Roussel Inc }\end{array}$ & MDL-105519 & $\begin{array}{l}\text { Neurodegenerative } \\
\text { disease }\end{array}$ & $\begin{array}{l}\text { Glycine antagonist; } \\
\text { NMDA receptor } \\
\text { antagonist }\end{array}$ & Neuroprotectant \\
\hline 295 & $\begin{array}{l}\text { No } \\
\text { Development } \\
\text { Reported }\end{array}$ & $\begin{array}{l}\text { Hoechst Marion } \\
\text { Roussel Inc }\end{array}$ & MDL-27266 & $\begin{array}{l}\text { Epilepsy; } \\
\text { Neurodegenerative } \\
\text { disease }\end{array}$ & $\begin{array}{l}\text { Glycine antagonist; } \\
\text { NMDA receptor } \\
\text { antagonist }\end{array}$ & $\begin{array}{l}\text { Ionotropic } \\
\text { glutamate receptor } \\
\text { antagonist; } \\
\text { Anticonvulsant } \\
\text { agent }\end{array}$ \\
\hline 296 & Discontinued & $\begin{array}{l}\text { Hoechst Marion } \\
\text { Roussel Inc }\end{array}$ & MDL-28170 & $\begin{array}{l}\text { Alzheimers disease; } \\
\text { Neurodegenerative } \\
\text { disease }\end{array}$ & $\begin{array}{l}\text { Cysteine protease } \\
\text { inhibitor; Hydrolase } \\
\text { inhibitor; Amyloid } \\
\text { protein deposition } \\
\text { inhibitor; Calpain } \\
\text { inhibitor }\end{array}$ & $\begin{array}{l}\text { Antiparasitic, } \\
\text { Neuroprotectant }\end{array}$ \\
\hline 297 & \begin{tabular}{|l|} 
No \\
Development \\
Reported \\
\end{tabular} & $\begin{array}{l}\text { Hoechst Marion } \\
\text { Roussel Inc }\end{array}$ & MDL-29951 & $\begin{array}{l}\text { Epilepsy; } \\
\text { Neurodegenerative } \\
\text { disease }\end{array}$ & $\begin{array}{l}\text { NMDA/Glycine } \\
\text { antagonist }\end{array}$ & $\begin{array}{l}\text { Anticonvulsant } \\
\text { agent }\end{array}$ \\
\hline 298 & Discontinued & Cephalon Inc; Chiron & mecasermin & $\begin{array}{l}\text { Diabetic } \\
\text { neuropathy; Motor } \\
\text { neurone disease; } \\
\text { Neurodegenerative } \\
\text { disease }\end{array}$ & $\begin{array}{l}\text { Insulin-like growth } \\
\text { factor } 1 \text { agonist }\end{array}$ & Neuroprotectant \\
\hline 299 & $\begin{array}{l}\text { Phase 1 } \\
\text { Clinical }\end{array}$ & $\begin{array}{l}\text { Bayer AG / Memory } \\
\text { Pharmaceuticals Corp }\end{array}$ & MEM-1003 & $\begin{array}{l}\text { Dementia, } \\
\text { Alzheimers Disease, } \\
\text { Cognitive disorder }\end{array}$ & $\begin{array}{l}\text { Calcium channel } \\
\text { modulator }\end{array}$ & Neuroprotectant \\
\hline 300 & $\begin{array}{l}\text { *Launched } \\
\text { (Phase } 3 \\
\text { Clinical) }\end{array}$ & Merz/Forrest & Memantine & $\begin{array}{l}\text { Neurodegenerative } \\
\text { disease }\end{array}$ & $\begin{array}{l}\text { NMDA receptor } \\
\text { antagonist }\end{array}$ & $\begin{array}{l}\text { Nueroprotectant; } \\
\text { Analgesic }\end{array}$ \\
\hline
\end{tabular}




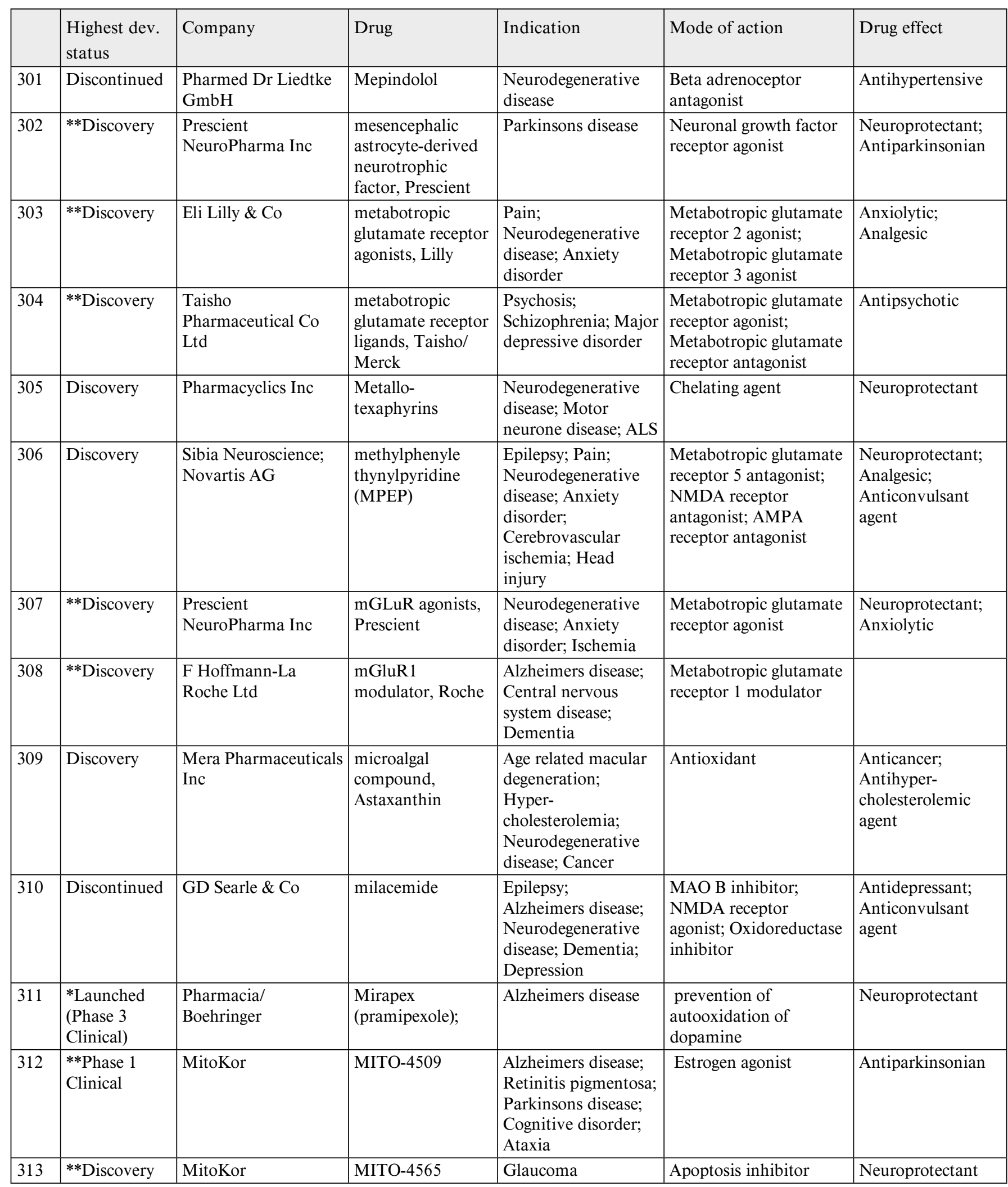




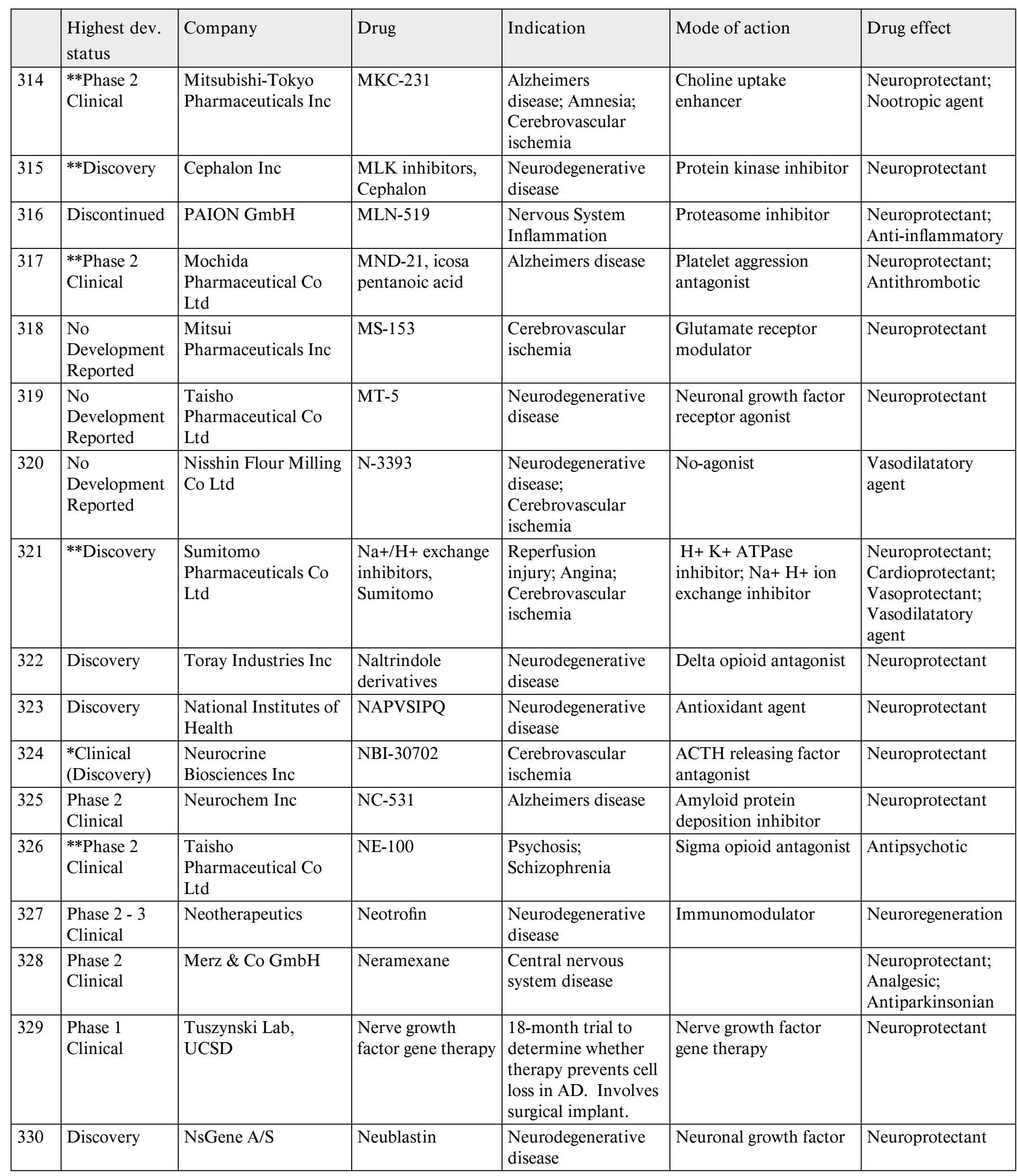




\begin{tabular}{|c|c|c|c|c|c|c|}
\hline & $\begin{array}{l}\text { Highest dev. } \\
\text { status }\end{array}$ & Company & Drug & Indication & Mode of action & Drug effect \\
\hline 331 & **Discovery & NeuroSpheres Ltd & $\begin{array}{l}\text { neural stem cells, } \\
\text { NeuroSpheres }\end{array}$ & $\begin{array}{l}\text { Alzheimers disease; } \\
\text { Huntingtons } \\
\text { chorea; Motor } \\
\text { neurone disease; } \\
\text { Multiple sclerosis; } \\
\text { Neurodegenerative } \\
\text { disease; } \\
\text { Parkinsons disease; } \\
\text { Schizophrenia; } \\
\text { Central nervous } \\
\text { system disease; } \\
\text { Cerebrovascular } \\
\text { ischemia }\end{array}$ & $\begin{array}{l}\text { Tissue regeneration } \\
\text { from stem cells }\end{array}$ & $\begin{array}{l}\text { Antipsychotic; } \\
\text { Antiparkinsonian }\end{array}$ \\
\hline 332 & **Discovery & $\begin{array}{l}\text { Harvard University/ } \\
\text { Acorda }\end{array}$ & $\begin{array}{l}\text { neuregulin-2, } \\
\text { Acorda }\end{array}$ & $\begin{array}{l}\text { Heart disease; } \\
\text { Neurological disease }\end{array}$ & $\begin{array}{l}\text { Erbb2 tyrosine kinase } \\
\text { receptor modulator; } \\
\text { Erbb3 tyrosine kinase } \\
\text { receptor modulator; } \\
\text { Erbb4 tyrosine kinase } \\
\text { receptor modulator; } \\
\text { Unspecified growth } \\
\text { factor agonist }\end{array}$ & $\begin{array}{l}\text { Neuroprotectant; } \\
\text { Cardioprotectant }\end{array}$ \\
\hline 333 & Discontinued & $\begin{array}{l}\text { Apollo } \\
\text { Biopharmaceutics Inc }\end{array}$ & Neurocalc & $\begin{array}{l}\text { Alzheimers disease; } \\
\text { Neurodegenerative } \\
\text { disease }\end{array}$ & $\begin{array}{l}\text { Calcium metabolism } \\
\text { modulator }\end{array}$ & Neuroprotectant \\
\hline 334 & **Discovery & $\begin{array}{l}\text { Johns Hopkins } \\
\text { University }\end{array}$ & $\begin{array}{l}\text { neuroimmuno- } \\
\text { philin ligands, } \\
\text { Guilford }\end{array}$ & \begin{tabular}{|l|} 
Diabetic neuropathy; \\
Alzheimers disease; \\
Multiple sclerosis; \\
Neurodegenerative \\
disease; Parkinsons \\
disease; \\
Cerebrovascular \\
disease; \\
Cerebrovascular \\
ischemia; \\
Neuropathy
\end{tabular} & $\begin{array}{l}\text { Immunophilin } \\
\text { modulator }\end{array}$ & $\begin{array}{l}\text { Chemoprotectant; } \\
\text { Neuroprotectant; } \\
\text { Antiparkinsonian }\end{array}$ \\
\hline 335 & **Discovery & $\begin{array}{l}\text { Acorda Therapeutics } \\
\text { Inc }\end{array}$ & $\begin{array}{l}\text { neuronal stem cell } \\
\text { therapy, Acorda }\end{array}$ & $\begin{array}{l}\text { Spinal cord injury; } \\
\text { Parkinsons disease }\end{array}$ & $\begin{array}{l}\text { Genetically engineered } \\
\text { autologous cell therapy; } \\
\text { regeneration from stem } \\
\text { cells }\end{array}$ & Antiparkinsonian \\
\hline 336 & **Discovery & \begin{tabular}{|l|} 
Vertex \\
Pharmaceuticals Inc
\end{tabular} & $\begin{array}{l}\text { neurophilins } \\
\text { (neurological } \\
\text { disease), Vertex/ } \\
\text { Schering }\end{array}$ & \begin{tabular}{|l|} 
Alzheimers disease; \\
Multiple sclerosis; \\
Parkinsons disease; \\
Arthritis; Psoriasis; \\
Autoimmune disease; \\
Neurological disease; \\
Diabetes mellitus
\end{tabular} & $\begin{array}{l}\text { General pump } \\
\text { inhibitors; P- } \\
\text { glycoprotein inhibitor }\end{array}$ & $\begin{array}{l}\text { Antiparkinsonian; } \\
\text { Immuno- } \\
\text { suppressant }\end{array}$ \\
\hline 337 & **Discovery & Renovis Inc & $\begin{array}{l}\text { neuroprotectants } \\
\text { (nitrone-based), } \\
\text { Renovis }\end{array}$ & \begin{tabular}{|l|} 
Cerebrovascular \\
ischemia; \\
Neurological disease; \\
Injury
\end{tabular} & Antioxidants & Neuroprotectant \\
\hline 338 & **Discovery & $\begin{array}{l}\text { Panacea } \\
\text { Pharmaceuticals Inc }\end{array}$ & $\begin{array}{l}\text { neuroprotective } \\
\text { antioxidants } \\
\text { (Alzheimers } \\
\text { disease), Panacea }\end{array}$ & $\begin{array}{l}\text { Alzheimers disease; } \\
\text { Ischemia }\end{array}$ & Antioxidants & $\begin{array}{l}\text { Neuroprotectant; } \\
\text { Antioxidant agent }\end{array}$ \\
\hline
\end{tabular}




\begin{tabular}{|c|c|c|c|c|c|c|}
\hline & $\begin{array}{l}\text { Highest dev. } \\
\text { status }\end{array}$ & Company & Drug & Indication & Mode of action & Drug effect \\
\hline 339 & \begin{tabular}{|l} 
No \\
Development \\
Reported \\
\end{tabular} & $\begin{array}{l}\text { Neurocal } \\
\text { International Inc }\end{array}$ & Neurostrol & $\begin{array}{l}\text { Alzheimers disease; } \\
\text { Neurodegenerative } \\
\text { disease }\end{array}$ & Antioxidants & Neuroprotectant \\
\hline 340 & $* *$ Discovery & BioVex Ltd & NeuroVEX & \begin{tabular}{|l|} 
Spinal cord \\
injury; Pain; \\
Neurodegenerative \\
disease; Parkinsons \\
disease \\
\end{tabular} & $\begin{array}{l}\text { Dopamine synthesis } \\
\text { stimulant; Herpes virus } \\
\text { based gene therapy; } \\
\text { Dopamine modulator }\end{array}$ & Antiparkinsonian \\
\hline 341 & **Discovery & $\begin{array}{l}\text { Institut Henri } \\
\text { Beaufour }\end{array}$ & $\begin{array}{l}\text { nitric oxide } \\
\text { synthase } \\
\text { inhibitors, Institut } \\
\text { Henri Beaufour } \\
\end{array}$ & $\begin{array}{l}\text { Neurodegenerative } \\
\text { disease; } \\
\text { Cerebrovascular } \\
\text { ischemia }\end{array}$ & NO synthesis inhibitor & $\begin{array}{l}\text { Neuroprotectant; } \\
\text { Free radical } \\
\text { scavenger }\end{array}$ \\
\hline 342 & Discontinued & AstraZeneca plc & $\begin{array}{l}\text { NLA-715; } \\
\text { Clomethiazole; } \\
\text { Zendra }\end{array}$ & $\begin{array}{l}\text { Epilepsy; } \\
\text { Cerebrovascular } \\
\text { ischemia, Parkinsons } \\
\text { disease, Epilepsy, } \\
\text { Alzheimers disease }\end{array}$ & GABA A agonist & $\begin{array}{l}\text { Neuroprotectant, } \\
\text { Anticonvulsant } \\
\text { agent }\end{array}$ \\
\hline 343 & **Discovery & $\begin{array}{l}\text { Hoffmann-La Roche } \\
\text { AG }\end{array}$ & $\begin{array}{l}\text { NMDA } \\
\text { antagonists, Roche }\end{array}$ & $\begin{array}{l}\text { Neurodegenerative } \\
\text { disease; Central } \\
\text { nervous } \\
\text { system disease; } \\
\text { Cerebrovascular } \\
\text { ischemia } \\
\end{array}$ & $\begin{array}{l}\text { NMDA receptor } \\
\text { antagonist }\end{array}$ & Neuroprotectant \\
\hline 344 & **Discovery & Hokkaido University & \begin{tabular}{|l|} 
NMDA \\
antagonists, \\
Hokkaido \\
University/Asahi \\
Kasei \\
\end{tabular} & $\begin{array}{l}\text { Neurodegenerative } \\
\text { disease }\end{array}$ & $\begin{array}{l}\text { NMDA receptor } \\
\text { antagonist }\end{array}$ & Neuroprotectant \\
\hline 345 & **Discovery & $\begin{array}{l}\text { Sumitomo } \\
\text { Pharmaceuticals Co } \\
\text { Ltd }\end{array}$ & $\begin{array}{l}\text { NMDA } \\
\text { antagonists, } \\
\text { Sumitomo }\end{array}$ & $\begin{array}{l}\text { Epilepsy; } \\
\text { Neurodegenerative } \\
\text { disease; } \\
\text { Cerebrovascular } \\
\text { ischemia }\end{array}$ & $\begin{array}{l}\text { NMDA/Glycine } \\
\text { antagonist; NMDA } \\
\text { receptor antagonist }\end{array}$ & $\begin{array}{l}\text { Neuroprotectant; } \\
\text { Anticonvulsant } \\
\text { agent }\end{array}$ \\
\hline 346 & $\begin{array}{l}* * \text { Phase } 1 \\
\text { Clinical } \\
\end{array}$ & Pfizer Inc & $\begin{array}{l}\text { NMDA/glycine } \\
\text { antagonists, Pfizer }\end{array}$ & $\begin{array}{l}\text { Cerebrovascular } \\
\text { ischemia }\end{array}$ & $\begin{array}{l}\text { NMDA/Glycine } \\
\text { antagonist }\end{array}$ & Neuroprotectant \\
\hline 347 & **Discovery & Merz \& Co GmbH & $\begin{array}{l}\text { NMDA glycine } \\
\text { site antagonists, } \\
\text { Merz }\end{array}$ & $\begin{array}{l}\text { Epilepsy; Pain; } \\
\text { Neurodegenerative } \\
\text { disease; } \\
\text { Cerebrovascular } \\
\text { ischemia } \\
\end{array}$ & $\begin{array}{l}\text { NMDA/Glycine } \\
\text { antagonist }\end{array}$ & $\begin{array}{l}\text { Neuroprotectant; } \\
\text { Analgesic; } \\
\text { Anticonvulsant } \\
\text { agent }\end{array}$ \\
\hline 348 & **Discovery & $\begin{array}{l}\text { Merck Sharp \& } \\
\text { Dohme Research } \\
\text { Laboratories }\end{array}$ & $\begin{array}{l}\text { NMDA receptor } \\
\text { antagonists (NR2B } \\
\text { subtype-selective), } \\
\text { Merck \& Co }\end{array}$ & $\begin{array}{l}\text { Epilepsy; } \\
\text { Neuropathic pain; } \\
\text { Parkinsons disease; } \\
\text { Cerebrovascular } \\
\text { ischemia }\end{array}$ & $\begin{array}{l}\text { NMDA receptor } \\
\text { antagonist }\end{array}$ & $\begin{array}{l}\text { Neuroprotectant; } \\
\text { Analgesic; } \\
\text { Antiparkinsonian; } \\
\text { Anticonvulsant } \\
\text { agent }\end{array}$ \\
\hline 349 & $\begin{array}{l}\text { No } \\
\text { Development } \\
\text { Reported }\end{array}$ & Novo Nordisk A/S & NNC-07-0775 & $\begin{array}{l}\text { Cerebrovascular } \\
\text { ischemia,; Epilepsy }\end{array}$ & $\begin{array}{l}\text { Metabotropic glutamate } \\
\text { receptor } 1 \text { antagonist, } \\
\text { Ionotropic glutamate } \\
\text { receptor antagonist }\end{array}$ & Neuroprotectant \\
\hline 350 & Discontinued & Novo Nordisk A/S & NNC-07-9202 & $\begin{array}{l}\text { Epilepsy; } \\
\text { Neurodegenerative } \\
\text { disease; Psychosis; } \\
\text { Cerebrovascular } \\
\text { ischemia }\end{array}$ & $\begin{array}{l}\text { Neuroprotectant; } \\
\text { NMDA receptor } \\
\text { antagonist; Ampa } \\
\text { receptor antagonist }\end{array}$ & $\begin{array}{l}\text { Neuroprotectant; } \\
\text { Antipsychotic; } \\
\text { Anticonvulsant } \\
\text { agent }\end{array}$ \\
\hline
\end{tabular}




\begin{tabular}{|c|c|c|c|c|c|c|}
\hline & $\begin{array}{l}\text { Highest dev. } \\
\text { status }\end{array}$ & Company & Drug & Indication & Mode of action & Drug effect \\
\hline 351 & $\begin{array}{l}\text { No } \\
\text { Development } \\
\text { Reported }\end{array}$ & $\begin{array}{l}\text { Regeneron } \\
\text { Pharmaceuticals Inc }\end{array}$ & Noggin & $\begin{array}{l}\text { Neurodegenerative } \\
\text { disease }\end{array}$ & Growth factor agonist & Neuroprotectant \\
\hline 352 & **Discovery & Biogen Inc & $\begin{array}{l}\text { Nogo receptor } \\
\text { modulators, } \\
\text { Biogen Idec }\end{array}$ & $\begin{array}{l}\text { Spinal cord injury; } \\
\text { Multiple sclerosis; } \\
\text { Cerebrovascular } \\
\text { ischemia; Brain } \\
\text { injury }\end{array}$ & $\begin{array}{l}\text { Neuronal growth factor } \\
\text { receptor modulator }\end{array}$ & Neuroprotectant \\
\hline 353 & **Discovery & Organix Inc & $\begin{array}{l}\text { nonamines, } \\
\text { Organix }\end{array}$ & $\begin{array}{l}\text { Parkinsons disease; } \\
\text { Central nervous } \\
\text { system disease; } \\
\text { Cocaine addiction }\end{array}$ & $\begin{array}{l}\text { Monoamine uptake } \\
\text { inhibitor }\end{array}$ & Antiparkinsonian \\
\hline 355 & $\begin{array}{l}\text { Phase 1 } \\
\text { Clinical }\end{array}$ & Medinox Inc & NOX-700 & $\begin{array}{l}\text { Neurodegenerative } \\
\text { disease }\end{array}$ & NO modulator & Antioxidant agent \\
\hline 356 & Discovery & $\begin{array}{l}\text { NPS Pharmaceuticals } \\
\text { Inc }\end{array}$ & NPS-1407 & $\begin{array}{l}\text { Epilepsy; Pain; } \\
\text { Neurodegenerative } \\
\text { disease; } \\
\text { Cerebrovascular } \\
\text { ischemia; Depression }\end{array}$ & $\begin{array}{l}\text { NMDA receptor } \\
\text { antagonist }\end{array}$ & $\begin{array}{l}\text { Antidepressant; } \\
\text { Analgesic; } \\
\text { Anticonvulsant } \\
\text { agent }\end{array}$ \\
\hline 357 & Discontinued & $\begin{array}{l}\text { NPS Pharmaceuticals } \\
\text { Inc }\end{array}$ & NPS-846 & $\begin{array}{l}\text { Epilepsy; Pain; } \\
\text { Neurodegenerative } \\
\text { disease; } \\
\text { Cerebrovascular } \\
\text { ischemia }\end{array}$ & $\begin{array}{l}\text { Ionotropic glutamate } \\
\text { receptor antagonist }\end{array}$ & $\begin{array}{l}\text { Neuroprotectant; } \\
\text { Anticonvulsant } \\
\text { agent }\end{array}$ \\
\hline 360 & Research Tool & NeuroSearch AS & NS-1608 & $\begin{array}{l}\text { Cerebrovascular } \\
\text { ischemia }\end{array}$ & $\begin{array}{l}\text { Potassium channel } \\
\text { activator }\end{array}$ & Neuroprotectant \\
\hline 361 & $\begin{array}{l}\text { Phase } 2 \\
\text { Clinical }\end{array}$ & NeuroSearch & NS-2330 & $\begin{array}{l}\text { Neurodegenerative } \\
\text { disease; Parkinsons } \\
\text { disease }\end{array}$ & $\begin{array}{l}\text { Dopamine reuptake } \\
\text { inhibitor }\end{array}$ & Neuroprotectant \\
\hline 362 & Discontinued & NeuroSearch AS & NS-257 & $\begin{array}{l}\text { Neurodegenerative } \\
\text { disease; } \\
\text { Cerebrovascular } \\
\text { ischemia }\end{array}$ & $\begin{array}{l}\text { AMPA receptor } \\
\text { antagonist }\end{array}$ & Neuroprotectant \\
\hline 363 & Discontinued & NeuroSearch AS & NS-377 & $\begin{array}{l}\text { Alzheimers disease; } \\
\text { Neurodegenerative } \\
\text { disease; Cognitive } \\
\text { disorder }\end{array}$ & $\begin{array}{l}\text { AMPA receptor } \\
\text { antagonist }\end{array}$ & Neuroprotectant \\
\hline 364 & Discontinued & NeuroSearch AS & NS-638 & $\begin{array}{l}\text { Neurodegenerative } \\
\text { disease; } \\
\text { Cerebrovascular } \\
\text { ischemia }\end{array}$ & Calcium channel blocker & $\begin{array}{l}\text { Neuroprotectant; } \\
\text { Vasodilatatory } \\
\text { agent }\end{array}$ \\
\hline
\end{tabular}




\begin{tabular}{|c|c|c|c|c|c|c|}
\hline & $\begin{array}{l}\text { Highest dev. } \\
\text { status }\end{array}$ & Company & Drug & Indication & Mode of action & Drug effect \\
\hline 365 & Discontinued & NeuroSearch AS & NS-649 & $\begin{array}{l}\text { Alzheimers disease; } \\
\text { Neurodegenerative } \\
\text { disease; Cognitive } \\
\text { disorder }\end{array}$ & Calcium channel blocker & Neuroprotectant \\
\hline 366 & $* *$ Discovery & $\begin{array}{l}\text { Genentech Inc/ } \\
\text { Ceregene }\end{array}$ & $\begin{array}{l}\text { NT-4/5, } \\
\text { Genentech }\end{array}$ & $\begin{array}{l}\text { Age related macular } \\
\text { degeneration; } \\
\text { Glaucoma; } \\
\text { Huntingtons chorea; } \\
\text { Motor neurone } \\
\text { disease; Parkinsons } \\
\text { disease; Uveitis; } \\
\text { Diabetic retinopathy; } \\
\text { Neurological disease; } \\
\text { Hearing disorder }\end{array}$ & $\begin{array}{l}\text { Neurotrophin- } 4 / 5 \\
\text { agonist }\end{array}$ & $\begin{array}{l}\text { Neuroprotectant; } \\
\text { Antiparkinsonian }\end{array}$ \\
\hline 368 & Discovery & $\begin{array}{l}\text { Nymox } \\
\text { Pharmaceutical Corp }\end{array}$ & NXD-5150 & $\begin{array}{l}\text { Neurodegenerative } \\
\text { disease }\end{array}$ & Unidentified & Neuroprotectant \\
\hline 369 & **Discovery & $\begin{array}{l}\text { Nymox } \\
\text { Pharmaceutical Corp }\end{array}$ & NXD-9062 & Alzheimers disease & $\begin{array}{l}\text { Spheron conversion } \\
\text { inhibitor }\end{array}$ & Neuroprotectant \\
\hline 370 & $\begin{array}{l}\text { Phase } 3 \\
\text { Clinical }\end{array}$ & $\begin{array}{l}\text { Centaur } \\
\text { Pharmaceuticals Inc, } \\
\text { Astra Zeneca plc }\end{array}$ & NXY-059 & $\begin{array}{l}\text { Alzheimers disease; } \\
\text { Multiple sclerosis; } \\
\text { Neurodegenerative } \\
\text { disease; Arthritis; } \\
\text { Cerebrovascular } \\
\text { ischemia }\end{array}$ & $\begin{array}{l}\text { Free radical scavenger; } \\
\text { NO synthesis inhibitor }\end{array}$ & Neuroprotectant \\
\hline 371 & $\begin{array}{l}* * \text { Phase } 2 \\
\text { Clinical }\end{array}$ & \begin{tabular}{|l} 
Janssen \\
Pharmaceutica NV
\end{tabular} & ocaperidone & Schizophrenia & $\begin{array}{l}\text { Dopamine D2 } \\
\text { antagonist; 5-HT 2a } \\
\text { antagonist }\end{array}$ & Antipsychotic \\
\hline 374 & $\begin{array}{l}* \text { Phase } 2 \\
\text { Clinical } \\
\text { (Phase } 1 \\
\text { Clinical) }\end{array}$ & $\begin{array}{l}\text { Ono Pharmaceutical } \\
\text { Co Ltd }\end{array}$ & ONO-2506 & \begin{tabular}{|l|} 
Cerebrovascular \\
Ischemia, Parkinsons \\
Disease
\end{tabular} & & $\begin{array}{l}\text { Neuroprotectant; } \\
\text { Antiparkinsonian }\end{array}$ \\
\hline 375 & $\begin{array}{l}\text { No } \\
\text { Development } \\
\text { Reported }\end{array}$ & $\begin{array}{l}\text { Otsuka } \\
\text { Pharmaceuticals Co } \\
\text { Ltd }\end{array}$ & OPC-14117 & $\begin{array}{l}\text { Dementia, } \\
\text { Cerebrovascular } \\
\text { ischemia, Dementia, } \\
\text { Huntingtons chorea }\end{array}$ & Free radical scavenger & $\begin{array}{l}\text { Neuroprotectant; } \\
\text { Antiparkinsonian }\end{array}$ \\
\hline 376 & $\begin{array}{l}* * \text { Phase } 2 \\
\text { Clinical }\end{array}$ & \begin{tabular}{|l|} 
Cortex \\
Pharmaceuticals Inc \\
\end{tabular} & Org-24448 & $\begin{array}{l}\text { Schizophrenia; Major } \\
\text { depressive disorder }\end{array}$ & $\begin{array}{l}\text { AMPA receptor } \\
\text { modulator }\end{array}$ & $\begin{array}{l}\text { Antidepressant; } \\
\text { Antipsychotic }\end{array}$ \\
\hline 377 & $\begin{array}{l}* * \text { Phase } 2 \\
\text { Clinical }\end{array}$ & Sanofi-Synthelabo & osanetant & $\begin{array}{l}\text { Phlebothrombosis; } \\
\text { Pain; Schizophrenia; } \\
\text { Deep vein } \\
\text { thrombosis; Major } \\
\text { depressive disorder }\end{array}$ & $\begin{array}{l}\text { NK agonist; NK3 } \\
\text { antagonist }\end{array}$ & $\begin{array}{l}\text { Anxiolytic; } \\
\text { Antipsychotic; } \\
\text { Antidepressant }\end{array}$ \\
\hline 378 & **Discovery & Serono SA & $\begin{array}{l}\text { osteopontin, } \\
\text { Serono }\end{array}$ & Multiple sclerosis & NOS inhibitor; Cytokine & Neuroprotectant \\
\hline
\end{tabular}




\begin{tabular}{|c|c|c|c|c|c|c|}
\hline & $\begin{array}{l}\text { Highest dev. } \\
\text { status }\end{array}$ & Company & Drug & Indication & Mode of action & Drug effect \\
\hline 379 & **Discovery & $\begin{array}{l}\text { National Institutes of } \\
\text { Health }\end{array}$ & $\begin{array}{l}\text { p53 inhibitors } \\
\text { (neuro- } \\
\text { degenerative } \\
\text { disease), NIH }\end{array}$ & $\begin{array}{l}\text { Neurodegenerative } \\
\text { disease; Toxicity }\end{array}$ & Apoptosis inhibitor & Neuroprotectant \\
\hline 380 & $\begin{array}{l}\text { Phase } 2 \\
\text { Clinical }\end{array}$ & Phytopharm plc & P-58 & $\begin{array}{l}\text { Dementia; } \\
\text { Alzheimers disease; } \\
\text { Parkinsons disease }\end{array}$ & $\begin{array}{l}\text { Muscarinic M1 } \\
\text { modulator }\end{array}$ & $\begin{array}{l}\text { Neuroprotectant; } \\
\text { Nootropic agent }\end{array}$ \\
\hline 381 & $\begin{array}{l}\text { No } \\
\text { Development } \\
\text { Reported }\end{array}$ & Aventis & P-9939 & $\begin{array}{l}\text { Neurodegenerative } \\
\text { disease }\end{array}$ & Glycine partial agonist & \\
\hline 382 & $\begin{array}{l}\text { Phase 1 } \\
\text { Clinical }\end{array}$ & Tulane University & PACAP & $\begin{array}{l}\text { Neurodegenerative } \\
\text { disease; } \\
\text { Cerebrovascular } \\
\text { ischemia }\end{array}$ & $\begin{array}{l}\text { Pituitary adenylate } \\
\text { cyclase activating } \\
\text { polypeptide (PACAP); } \\
\text { Adenylate cyclase } \\
\text { stimulator }\end{array}$ & Neuroprotectant \\
\hline 383 & $\begin{array}{l}* * \text { Phase } 3 \\
\text { Clinical }\end{array}$ & Johnson \& Johnson & paliperidone & Schizophrenia & 5-HT antagonist & Antipsychotic \\
\hline 384 & $\begin{array}{l}\text { Phase } 3 \\
\text { Clinical }\end{array}$ & Lifegroup SpA & palmidrol & $\begin{array}{l}\text { Neurodegenerative } \\
\text { disease; } \\
\text { Inflammation }\end{array}$ & 5-HT release inhibitor & $\begin{array}{l}\text { Neuroprotectant; } \\
\text { Anti-inflammatory }\end{array}$ \\
\hline 385 & Discovery & $\begin{array}{l}\text { Panacea } \\
\text { Pharmaceuticals Inc }\end{array}$ & PAN-811 & Alzheimers disease & Antioxidant agent & Neuroprotectant \\
\hline 386 & $\begin{array}{l}\text { No } \\
\text { Development } \\
\text { Reported }\end{array}$ & $\begin{array}{l}\text { Regeneron } \\
\text { Pharmaceuticals Inc }\end{array}$ & $\begin{array}{l}\text { Pan-Neurotrophin- } \\
1\end{array}$ & $\begin{array}{l}\text { Alzheimers disease; } \\
\text { Neurodegenerative } \\
\text { disease; Psychosis }\end{array}$ & $\begin{array}{l}\text { Unspecified growth } \\
\text { factor agonist }\end{array}$ & $\begin{array}{l}\text { Neuroprotectant; } \\
\text { Antipsychotic }\end{array}$ \\
\hline 387 & $* *$ Discovery & CellFactors plc & $\begin{array}{l}\text { Parkinsons disease } \\
\text { cell therapy, Cell } \\
\text { Factors }\end{array}$ & Parkinsons disease & Cell therapy & Antiparkinsonian \\
\hline 388 & **Discovery & $\begin{array}{l}\text { Boston Life Sciences } \\
\text { Inc }\end{array}$ & $\begin{array}{l}\text { Parkinsons disease } \\
\text { therapeutics, } \\
\text { Boston Life } \\
\text { Sciences }\end{array}$ & $\begin{array}{l}\text { Parkinsons disease; } \\
\text { Attention deficit } \\
\text { hyperactivity } \\
\text { disorder }\end{array}$ & $\begin{array}{l}\text { Dopamine uptake } \\
\text { inhibitor }\end{array}$ & Antiparkinsonian \\
\hline 389 & **Discovery & $\begin{array}{l}\text { Panacea } \\
\text { Pharmaceuticals Inc }\end{array}$ & $\begin{array}{l}\text { Parkinsons } \\
\text { therapeutic } \\
\text { peptides, Panacea }\end{array}$ & Parkinsons disease & Antiparkinsonian & \\
\hline 390 & **Discovery & $\begin{array}{l}\text { Johns Hopkins } \\
\text { University }\end{array}$ & $\begin{array}{l}\text { PARP inhibitors, } \\
\text { Guilford }\end{array}$ & $\begin{array}{l}\text { Diabetic neuropathy; } \\
\text { Spinal cord injury; } \\
\text { Alzheimers disease; } \\
\text { Myocardial } \\
\text { infarction; } \\
\text { Neurodegenerative } \\
\text { disease; } \\
\text { Parkinsons disease; } \\
\text { Cerebrovascular } \\
\text { ischemia; Cancer; } \\
\text { Head injury; Septic } \\
\text { shock } \\
\end{array}$ & PARP inhibitor & $\begin{array}{l}\text { Radiosensitizer; } \\
\text { Neuroprotectant; } \\
\text { Antiparkinsonian }\end{array}$ \\
\hline 391 & **Discovery & Cephalon Inc & $\begin{array}{l}\text { PARP-1 inhibitor, } \\
\text { Cephalon }\end{array}$ & $\begin{array}{l}\text { Cerebrovascular } \\
\text { ischemia; Cancer }\end{array}$ & PARP inhibitor & $\begin{array}{l}\text { Anticancer; } \\
\text { Neuroprotectant }\end{array}$ \\
\hline 392 & **Discovery & $\begin{array}{l}\text { Fujisawa } \\
\text { Pharmaceutical Co } \\
\text { Ltd }\end{array}$ & $\begin{array}{l}\text { PARP-1 inhibitors, } \\
\text { Fujisawa }\end{array}$ & Parkinsons disease & PARP inhibitor & \\
\hline
\end{tabular}




\begin{tabular}{|c|c|c|c|c|c|c|}
\hline & $\begin{array}{l}\text { Highest dev. } \\
\text { status }\end{array}$ & Company & Drug & Indication & Mode of action & Drug effect \\
\hline 393 & **Discovery & $\begin{array}{l}\text { Sumitomo } \\
\text { Pharmaceuticals Co } \\
\text { Ltd }\end{array}$ & $\begin{array}{l}\text { PARP-1 inhibitors } \\
\text { (stroke), Sumitomo }\end{array}$ & $\begin{array}{l}\text { Cerebrovascular } \\
\text { ischemia }\end{array}$ & PARP inhibitor & Neuroprotectant \\
\hline 394 & **Discovery & $\begin{array}{l}\text { University of } \\
\text { Florence }\end{array}$ & $\begin{array}{l}\text { PARP-1 inhibitors, } \\
\text { University } \\
\text { of Florence/ } \\
\text { GlaxoSmithKline }\end{array}$ & $\begin{array}{l}\text { Cerebrovascular } \\
\text { ischemia }\end{array}$ & PARP inhibitor & Neuroprotectant \\
\hline 395 & $\begin{array}{l}\text { Phase } 2 \\
\text { Clinical }\end{array}$ & Prana Biotechnology & PBT-1; Clioquinol & Alzheimers disease & $\begin{array}{l}\text { Chelating agent; Beta } \\
\text { amyloid modulator }\end{array}$ & Neuroprotectant \\
\hline 396 & $\begin{array}{l}\text { No } \\
\text { Development } \\
\text { Reported }\end{array}$ & Parke-Davis \& Co & PD-132026 & $\begin{array}{l}\text { Neurodegenerative } \\
\text { disease }\end{array}$ & Dopamine agonist & $\begin{array}{l}\text { Neuroprotectant; } \\
\text { Antipsychotic }\end{array}$ \\
\hline 399 & Discovery & Pfizer Inc & PD-159265 & $\begin{array}{l}\text { Neurodegenerative } \\
\text { disease }\end{array}$ & $\begin{array}{l}\text { AMPA receptor } \\
\text { antagonist }\end{array}$ & Neuroprotectant \\
\hline 400 & $\begin{array}{l}\text { No } \\
\text { Development } \\
\text { Reported }\end{array}$ & Parke-Davis \& Co & PD-90780 & $\begin{array}{l}\text { Nervous } \\
\text { system tumor; } \\
\text { Neurodegenerative } \\
\text { disease }\end{array}$ & NGF antagonist & Neuroprotectant \\
\hline 401 & $\begin{array}{l}\text { No } \\
\text { Development } \\
\text { Reported }\end{array}$ & $\begin{array}{l}\text { Pharmaceutical } \\
\text { Discovery Corp }\end{array}$ & PDC-008.004 & $\begin{array}{l}\text { Alzheimers disease; } \\
\text { Neurodegenerative } \\
\text { disease }\end{array}$ & Muscarinic M2 agonist & Nootropic agent \\
\hline 404 & $\begin{array}{l}* * \text { Phase } 2 \\
\text { Clinical }\end{array}$ & Wyeth Research & perzinfotel & $\begin{array}{l}\text { Pain; } \\
\text { Cerebrovascular } \\
\text { ischemia; } \\
\text { Neuropathy }\end{array}$ & $\begin{array}{l}\text { NMDA receptor } \\
\text { antagonist }\end{array}$ & $\begin{array}{l}\text { Neuroprotectant; } \\
\text { Analgesic }\end{array}$ \\
\hline 405 & **Discovery & $\begin{array}{l}\text { Alexion } \\
\text { Pharmaceuticals Inc }\end{array}$ & pexelizumab & $\begin{array}{l}\text { Myocardial } \\
\text { infarction; Angina; } \\
\text { Cardiovascular } \\
\text { inflammation; } \\
\text { Cerebrovascular } \\
\text { ischemia }\end{array}$ & $\begin{array}{l}\text { Complement cascade } \\
\text { inhibitor }\end{array}$ & $\begin{array}{l}\text { Cardioprotectant; } \\
\text { Vasoprotectant }\end{array}$ \\
\hline 406 & $\begin{array}{l}\text { *Phase } 3 \\
\text { Clinical } \\
\text { (Discovery) }\end{array}$ & Axonyx Inc/NIH & Phenserine; & Alzheimers disease & $\begin{array}{l}\text { Acetylcholinesterase } \\
\text { inhibitor }\end{array}$ & Anti-amyloidogenic \\
\hline 407 & Discovery & $\begin{array}{l}\text { University of } \\
\text { Nottingham }\end{array}$ & Philanthotoxins & $\begin{array}{l}\text { Neurodegenerative } \\
\text { disease; Cognitive } \\
\text { disorder }\end{array}$ & $\begin{array}{l}\text { Nicotinic ACh } \\
\text { antagonist; AMPA } \\
\text { receptor antagonist }\end{array}$ & Nootropic agent \\
\hline
\end{tabular}




\begin{tabular}{|c|c|c|c|c|c|c|}
\hline & $\begin{array}{l}\text { Highest dev. } \\
\text { status }\end{array}$ & Company & Drug & Indication & Mode of action & Drug effect \\
\hline 408 & $\begin{array}{l}\text { *No } \\
\text { Development } \\
\text { Reported } \\
\text { (Discovery) }\end{array}$ & Pierre Fabre SA & $\begin{array}{l}\text { Piperidine } \\
\text { derivatives }\end{array}$ & $\begin{array}{l}\text { Alzheimers disease; } \\
\text { Neurodegenerative } \\
\text { disease; Parkinsons } \\
\text { disease }\end{array}$ & $\begin{array}{l}\text { Alpha } 1 \text { adrenoceptor } \\
\text { antagonist; Alpha } 2 \\
\text { adrenoceptor antagonist }\end{array}$ & Antiparkinsonian \\
\hline 409 & Discovery & Universita di Siena & PK-11195 analogs & $\begin{array}{l}\text { Neurodegenerative } \\
\text { disease; Anxiety } \\
\text { disorder }\end{array}$ & $\begin{array}{l}\text { Dopamine D2 } \\
\text { antagonist; 5-HT 1a } \\
\text { antagonist; Glutamate } \\
\text { release inhibitor }\end{array}$ & $\begin{array}{l}\text { Anxiolytic; Imaging } \\
\text { agent; BDZ agonist }\end{array}$ \\
\hline 410 & Discovery & $\begin{array}{l}\text { Proneuron } \\
\text { Biotechnologies Inc }\end{array}$ & PN-277 & $\begin{array}{l}\text { Neurodegenerative } \\
\text { disease }\end{array}$ & & $\begin{array}{l}\text { Neuroprotectant; } \\
\text { Immunomodulator }\end{array}$ \\
\hline 411 & **Discovery & $\begin{array}{l}\text { Wellstat Therapeutics } \\
\text { Corp }\end{array}$ & PN-401 & $\begin{array}{l}\text { Leukopenia, } \\
\text { drug induced; } \\
\text { Stomach tumor; } \\
\text { Gastrointestinal } \\
\text { tumor; } \\
\text { Neurodegenerative } \\
\text { disease; Pancreas } \\
\text { tumor; Colorectal } \\
\text { tumor }\end{array}$ & $\begin{array}{l}\text { Uracil metabolism } \\
\text { modulator }\end{array}$ & $\begin{array}{l}\text { Anticancer; } \\
\text { Neuroprotectant }\end{array}$ \\
\hline 412 & Discontinued & $\begin{array}{l}\text { Pharmacia \& Upjohn } \\
\text { Inc }\end{array}$ & PNU-87663 & $\begin{array}{l}\text { Neurodegenerative } \\
\text { disease }\end{array}$ & $\begin{array}{l}\text { Coagulation inhibitor; } \\
\text { Antithrombin III }\end{array}$ & Antioxidant agent \\
\hline 413 & $\begin{array}{l}* * \text { Research } \\
\text { Tool } \\
\end{array}$ & $\begin{array}{l}\text { Pharmacia \& Upjohn } \\
\text { Inc }\end{array}$ & PNU-99194A & Schizophrenia & $\begin{array}{l}\text { Dopamine D3 } \\
\text { antagonist }\end{array}$ & Antipsychotic \\
\hline 414 & $\begin{array}{l}\text { No } \\
\text { Development } \\
\text { Reported }\end{array}$ & $\begin{array}{l}\text { Pharmacia \& Upjohn } \\
\text { Inc }\end{array}$ & PNU-101033E & $\begin{array}{l}\text { Neurodegenerative } \\
\text { disease; Ischemia }\end{array}$ & & $\begin{array}{l}\text { Neuroprotectant; } \\
\text { Antioxidant agent }\end{array}$ \\
\hline 415 & \begin{tabular}{|l|} 
No \\
Development \\
Reported \\
\end{tabular} & $\begin{array}{l}\text { Pharmacia \& Upjohn } \\
\text { Inc }\end{array}$ & PNU-157678 & $\begin{array}{l}\text { Neurodegenerative } \\
\text { disease }\end{array}$ & $\begin{array}{l}\text { Unclassified enzyme } \\
\text { inhibitor }\end{array}$ & Neuroprotectant \\
\hline 419 & $* *$ Discovery & University of Kuopio & $\begin{array}{l}\text { POP inhibitor } \\
\text { (Alzheimers), } \\
\text { Finncovery/ } \\
\text { University of } \\
\text { Kuopio }\end{array}$ & Alzheimers disease & $\begin{array}{l}\text { Prolylendopeptidase } \\
\text { inhibitor }\end{array}$ & Neuroprotectant \\
\hline 420 & Discontinued & Gedeon Richter Ltd & posatirelin & $\begin{array}{l}\text { Neurodegenerative } \\
\text { disease }\end{array}$ & TRH agonist & Neuroprotectant \\
\hline 421 & **Discovery & $\begin{array}{l}\text { Bristol-Myers Squibb } \\
\text { Co }\end{array}$ & $\begin{array}{l}\text { potassium channel } \\
\text { modulators, BMS }\end{array}$ & $\begin{array}{l}\text { Cerebrovascular } \\
\text { ischemia }\end{array}$ & $\begin{array}{l}\text { Potassium channel } \\
\text { modulator }\end{array}$ & Neuroprotectant \\
\hline 422 & \begin{tabular}{|l|} 
No \\
Development \\
Reported
\end{tabular} & $\begin{array}{l}\text { Praecis } \\
\text { Pharmaceuticals Inc }\end{array}$ & PPI-368 & $\begin{array}{l}\text { Alzheimers disease; } \\
\text { Neurodegenerative } \\
\text { disease }\end{array}$ & $\begin{array}{l}\text { Amyloid protein } \\
\text { deposition inhibitor }\end{array}$ & Neuroprotectant \\
\hline 423 & Discovery & $\begin{array}{l}\text { Prescient } \\
\text { NeuroPharma Inc }\end{array}$ & PRE-103 & $\begin{array}{l}\text { Neurodegenerative } \\
\text { disease; Anxiety } \\
\text { disorder; Ischemia }\end{array}$ & $\begin{array}{l}\text { Metabotropic glutamate } \\
\text { receptor agonist }\end{array}$ & $\begin{array}{l}\text { Neuroprotectant; } \\
\text { Anxiolytic }\end{array}$ \\
\hline
\end{tabular}




\begin{tabular}{|c|c|c|c|c|c|c|}
\hline & $\begin{array}{l}\text { Highest dev. } \\
\text { status }\end{array}$ & Company & Drug & Indication & Mode of action & Drug effect \\
\hline 424 & Discontinued & $\begin{array}{l}\text { Takeda Chemical } \\
\text { Industries Ltd }\end{array}$ & Protirelin & $\begin{array}{l}\text { Alzheimers disease; } \\
\text { Neurodegenerative } \\
\text { disease; Dementia }\end{array}$ & TRH agonist & Nootropic agent \\
\hline 425 & Discovery & Pharmos Corp & \begin{tabular}{|l|} 
PRS-211220 \\
\end{tabular} & \begin{tabular}{|l|} 
Multiple sclerosis; \\
Neurodegenerative \\
disease; Parkinsons \\
disease; \\
Cerebrovascular \\
ischemia; Nervous \\
system inflammation; \\
Brain injury \\
\end{tabular} & $\begin{array}{l}\text { Cyclooxygenase } 2 \\
\text { inhibitor; Chemokine } \\
\text { antagonist; NMDA } \\
\text { receptor antagonist; } \\
\text { Cannabinoid agonist; } \\
\text { Cytokine modulator }\end{array}$ & $\begin{array}{l}\text { Neuroprotectant; } \\
\text { Analgesic; } \\
\text { Antiparkinsonian; } \\
\text { Non-steroidal anti- } \\
\text { inflammatory }\end{array}$ \\
\hline 426 & **Discovery & ProteoTech Inc & PTI-777 & $\begin{array}{l}\text { Amyloidosis; } \\
\text { Alzheimers disease; } \\
\text { Parkinsons disease; } \\
\text { Non-insulin } \\
\text { dependent diabetes }\end{array}$ & $\begin{array}{l}\text { Amyloid protein } \\
\text { deposition inhibitor }\end{array}$ & Neuroprotectant \\
\hline 427 & $\begin{array}{l}* * \text { Phase } 1 \\
\text { Clinical }\end{array}$ & Phytopharm plc & PYM-50018 & $\begin{array}{l}\text { Motor neurone } \\
\text { disease; } \\
\text { Neuromuscular } \\
\text { disease; Cardiac } \\
\text { failure }\end{array}$ & $\begin{array}{l}\beta \text {-adrenoceptor } \\
\text { antagonist }\end{array}$ & $\begin{array}{l}\text { Neuroprotectant; } \\
\text { Cardioprotectant }\end{array}$ \\
\hline 428 & $\begin{array}{l}\text { Phase } 2 \\
\text { Clinical }\end{array}$ & Phytopharm plc & PYM-50028 & $\begin{array}{l}\text { Alzheimers disease; } \\
\text { Neurodegenerative } \\
\text { disease; Parkinsons } \\
\text { disease }\end{array}$ & Dopamine modulator & $\begin{array}{l}\text { Neuroprotectant; } \\
\text { Nootropic agent }\end{array}$ \\
\hline 429 & **Discovery & $\begin{array}{l}\text { Ferrer Internacional } \\
\text { SA }\end{array}$ & pyrimidin-5-one & Schizophrenia & & Antipsychotic \\
\hline 430 & Discovery & Quark Biotech Inc & QG-2283 & $\begin{array}{l}\text { Neurodegenerative } \\
\text { disease }\end{array}$ & Hypoxia protection & Neuroprotectant \\
\hline 431 & $\begin{array}{l}* * \text { Phase } 2 \\
\text { Clinical }\end{array}$ & Quigley Pharma Inc & QR-333 & Diabetic neuropathy & $\begin{array}{l}\text { Carbohydrate } \\
\text { metabolism modulator }\end{array}$ & Neuroprotectant \\
\hline 432 & $\begin{array}{l}* * \text { Phase } 1 \\
\text { Clinical }\end{array}$ & Roche Holding AG & R-1485 & Alzheimers disease & $\begin{array}{l}\text { Unspecified GPCR } \\
\text { modulator }\end{array}$ & Neuroprotectant \\
\hline 433 & **Discovery & Roche Holding AG & R-1577 & Alzheimers disease & $\begin{array}{l}\text { Unclassified enzyme } \\
\text { inhibitor }\end{array}$ & Neuroprotectant \\
\hline 434 & **Discovery & Roche Holding AG & & Alzheimers disease & $\begin{array}{l}\text { Unspecified GPCR } \\
\text { modulator }\end{array}$ & Neuroprotectant \\
\hline 435 & \begin{tabular}{|l|} 
*Pre- \\
registration \\
(Phase 3 \\
Clinical) \\
\end{tabular} & $\begin{array}{l}\text { Teva Pharmaceutical } \\
\text { Industries Ltd }\end{array}$ & Rasagiline & $\begin{array}{l}\text { Alzheimers disease; } \\
\text { Neurodegenerative } \\
\text { disease; Parkinsons } \\
\text { disease }\end{array}$ & $\begin{array}{l}\text { Apoptosis inhibitor; } \\
\text { MAO B inhibitor }\end{array}$ & Antiparkinsonian \\
\hline 436 & Discontinued & $\begin{array}{l}\text { Centaur } \\
\text { Pharmaceuticals Inc }\end{array}$ & REN-1654 & $\begin{array}{l}\text { Alzheimers disease, } \\
\text { Multiple sclerosis }\end{array}$ & Anti-inflammatory & $\begin{array}{l}\text { Neuroprotectant, } \\
\text { Antiparkinsonian }\end{array}$ \\
\hline 437 & Discovery & ReNeuron (UK) Ltd & ReN-1820 & $\begin{array}{l}\text { Alzheimers disease; } \\
\text { Inflammation; Pain; } \\
\text { Neurodegenerative } \\
\text { disease; Dementia }\end{array}$ & NGF antagonist & $\begin{array}{l}\text { Nootropic agent; } \\
\text { Analgesic; Anti- } \\
\text { inflammatory }\end{array}$ \\
\hline 438 & $\begin{array}{l}* * \text { Phase } 2 \\
\text { Clinical }\end{array}$ & Bayer AG & repinotan & $\begin{array}{l}\text { Cerebrovascular } \\
\text { ischemia; Brain } \\
\text { injury; Major } \\
\text { depressive disorder }\end{array}$ & 5-HT 1a agonist & $\begin{array}{l}\text { Neuroprotectant; } \\
\text { Antidepressant }\end{array}$ \\
\hline
\end{tabular}




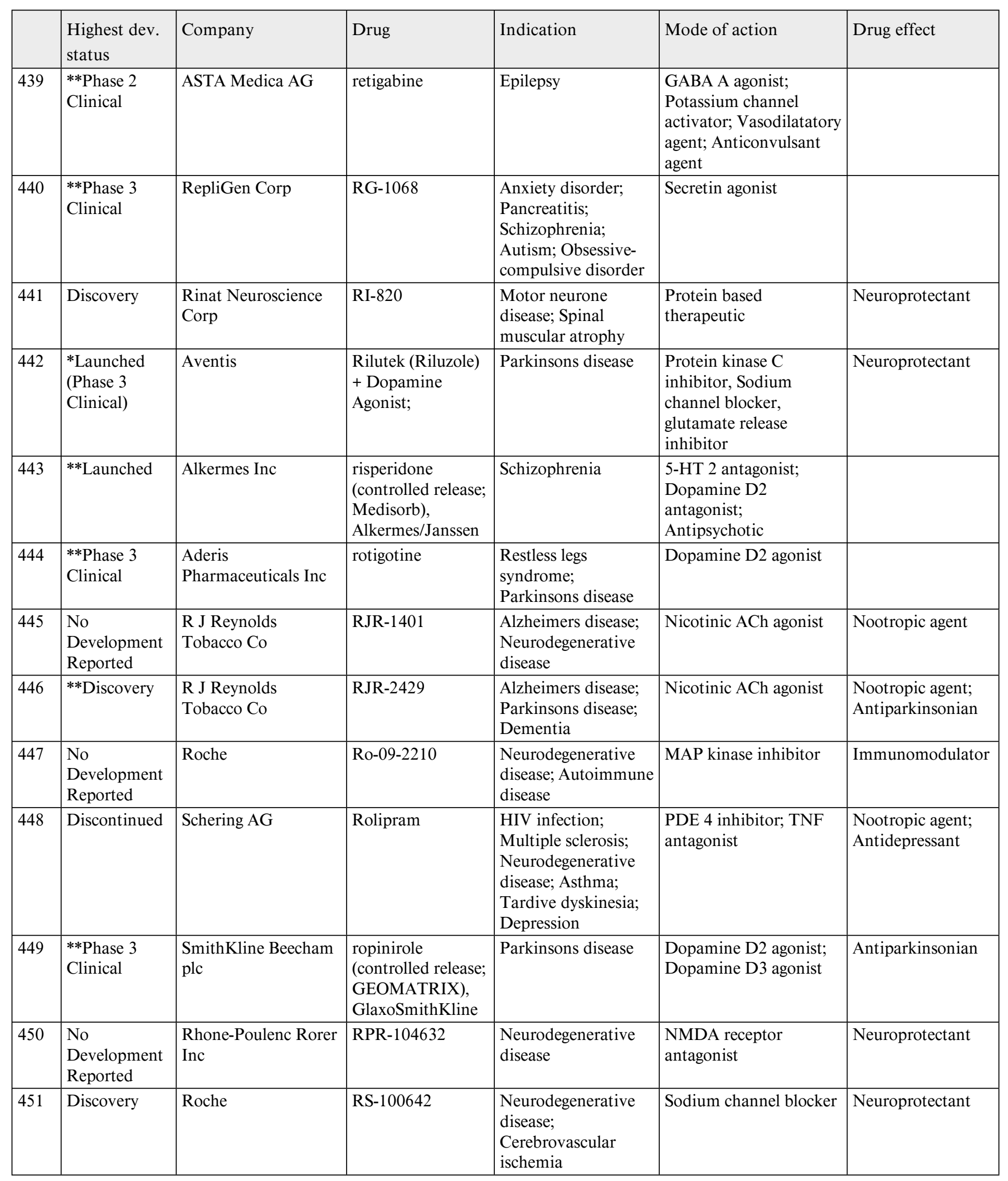




\begin{tabular}{|c|c|c|c|c|c|c|}
\hline & $\begin{array}{l}\text { Highest dev. } \\
\text { status }\end{array}$ & Company & Drug & Indication & Mode of action & Drug effect \\
\hline 452 & Discontinued & Shionogi \& Co Ltd & S-312-d & $\begin{array}{l}\text { Neurodegenerative } \\
\text { disease; } \\
\text { Cerebrovascular } \\
\text { ischemia }\end{array}$ & Calcium channel blocker & $\begin{array}{l}\text { Antihypertensive; } \\
\text { Class IV } \\
\text { antiarrhythmic } \\
\text { agent }\end{array}$ \\
\hline 453 & $\begin{array}{l}* * \text { Phase } 1 \\
\text { Clinical }\end{array}$ & Shionogi \& Co Ltd & S-1746 & $\begin{array}{l}\text { Cerebrovascular } \\
\text { ischemia; Head } \\
\text { injury }\end{array}$ & $\begin{array}{l}\text { NMDA receptor } \\
\text { modulator; AMPA } \\
\text { receptor antagonist }\end{array}$ & Neuroprotectant \\
\hline 454 & **Discovery & Servier & S-14297 & $\begin{array}{l}\text { Psychosis; } \\
\text { Schizophrenia }\end{array}$ & $\begin{array}{l}\text { Dopamine D3 } \\
\text { antagonist; 5-HT 2a } \\
\text { antagonist }\end{array}$ & Antipsychotic \\
\hline 455 & $\begin{array}{l}\text { No } \\
\text { Development } \\
\text { Reported }\end{array}$ & Servier & S-14820 & $\begin{array}{l}\text { Neurodegenerative } \\
\text { disease; Central } \\
\text { nervous system } \\
\text { disease }\end{array}$ & TRH agonist & Neuroprotectant \\
\hline 456 & Discovery & Servier & $\begin{array}{l}\text { S-176251; S- } \\
\text { 34730-1; S-34730 }\end{array}$ & $\begin{array}{l}\text { Neurodegenerative } \\
\text { disease; } \\
\text { Cerebrovascular } \\
\text { ischemia; Seizure, } \\
\text { epilepsy \& } \\
\text { convulsion } \\
\end{array}$ & $\begin{array}{l}\text { AMPA receptor } \\
\text { antagonist }\end{array}$ & $\begin{array}{l}\text { Neuroprotectant; } \\
\text { Anticonvulsant } \\
\text { agent }\end{array}$ \\
\hline 457 & $\begin{array}{l}\text { *Phase } 1 \\
\text { Clinical } \\
\text { (Discovery) }\end{array}$ & Servier & S-18986 & $\begin{array}{l}\text { Neurodegenerative } \\
\text { disease; Cognitive } \\
\text { disorder; } \\
\text { Cerebrovascular } \\
\text { ischemia }\end{array}$ & $\begin{array}{l}\text { Glutamate receptor } \\
\text { antagonist; AMPA } \\
\text { receptor modulator }\end{array}$ & Neuroprotectant \\
\hline 458 & Discovery & Servier & S-33113-1 & $\begin{array}{l}\text { Neurodegenerative } \\
\text { disease; } \\
\text { Cerebrovascular } \\
\text { ischemia }\end{array}$ & Antioxidant agent & Neuroprotectant \\
\hline 459 & $* *$ Discovery & Servier & S-33138 & $\begin{array}{l}\text { Psychosis; } \\
\text { Schizophrenia }\end{array}$ & $\begin{array}{l}\text { Dopamine D3 } \\
\text { antagonist }\end{array}$ & Antipsychotic \\
\hline 460 & Discontinued & \begin{tabular}{|l|} 
Janssen \\
Pharmaceutica \\
\end{tabular} & sabeluzole & $\begin{array}{l}\text { Alzheimers disease; } \\
\text { Dementia }\end{array}$ & Hypoxia protection & Neuroprotectant \\
\hline 461 & $\begin{array}{l}\text { Phase } 2 \\
\text { Clinical }\end{array}$ & $\begin{array}{l}\text { Newron } \\
\text { Pharmaceuticals SpA }\end{array}$ & Safinamide & $\begin{array}{l}\text { Parkinsons disease; } \\
\text { Epilepsy }\end{array}$ & $\begin{array}{l}\text { Calcium channel } \\
\text { blocker; Dopamine } \\
\text { uptake inhibitor }\end{array}$ & $\begin{array}{l}\text { Neuroprotectant; } \\
\text { Antiparkinsonian }\end{array}$ \\
\hline 462 & $\begin{array}{l}* * \text { Phase } 2 \\
\text { Clinical }\end{array}$ & Merck KGaA & sarizotan & $\begin{array}{l}\text { Parkinsons } \\
\text { disease; Psychosis; } \\
\text { Schizophrenia; } \\
\text { Tardive dyskinesia }\end{array}$ & $\begin{array}{l}\text { Dopamine antagonist; } \\
\text { Dopamine D2 } \\
\text { antagonist; 5-HT 1a } \\
\text { agonist }\end{array}$ & $\begin{array}{l}\text { Antipsychotic; } \\
\text { Antiparkinsonian }\end{array}$ \\
\hline 463 & $\begin{array}{l}* * \text { Research } \\
\text { Tool }\end{array}$ & $\begin{array}{l}\text { SmithKline Beecham } \\
\text { plc }\end{array}$ & SB-203580 & $\begin{array}{l}\text { Alzheimers disease; } \\
\text { Inflammation; } \\
\text { Rheumatoid } \\
\text { arthritis; Asthma; } \\
\text { Ischemia; } \\
\text { Cerebrovascular } \\
\text { ischemia; Vascular } \\
\text { disease }\end{array}$ & $\begin{array}{l}\text { Cytokine release } \\
\text { inhibitor; p38 MAP } \\
\text { kinase inhibitor; Anti- } \\
\text { inflammatory }\end{array}$ & $\begin{array}{l}\text { Neuroprotectant; } \\
\text { Vasoprotectant }\end{array}$ \\
\hline 464 & Discontinued & GlaxoSmithKline plc & SB-271046 & $\begin{array}{l}\text { Alzheimers disease; } \\
\text { Schizophrenia }\end{array}$ & 5-HT antagonist & Antipsychotic \\
\hline 465 & Discovery & GlaxoSmithKline plc & SB-277011 & Schizophrenia & $\begin{array}{l}\text { Dopamine D3 } \\
\text { antagonist }\end{array}$ & Antipsychotic \\
\hline
\end{tabular}




\begin{tabular}{|c|c|c|c|c|c|c|}
\hline & $\begin{array}{l}\text { Highest dev. } \\
\text { status }\end{array}$ & Company & Drug & Indication & Mode of action & Drug effect \\
\hline 466 & $\begin{array}{l}* * \text { Phase } 1 \\
\text { Clinical }\end{array}$ & Wyeth & SCA-136 & Schizophrenia & 5-HT modulator & Psychomodulator \\
\hline 467 & $\begin{array}{l}* * \text { Research } \\
\text { Tool }\end{array}$ & Schering-Plough Corp & Sch-58261 & $\begin{array}{l}\text { Neurodegenerative } \\
\text { disease; Parkinsons } \\
\text { disease; Neurological } \\
\text { disease }\end{array}$ & $\begin{array}{l}\text { Adenosine A2a } \\
\text { antagonist }\end{array}$ & \\
\hline 469 & $\begin{array}{l}\text { Phase } 2 \\
\text { Clinical }\end{array}$ & $\begin{array}{l}\text { Russian Academy of } \\
\text { Sciences }\end{array}$ & SEMAX & $\begin{array}{l}\text { Alzheimers disease; } \\
\text { Neurodegenerative } \\
\text { disease; } \\
\text { Cerebrovascular } \\
\text { ischemia }\end{array}$ & ACTH agonist & $\begin{array}{l}\text { Neuroprotectant; } \\
\text { Vasoprotectant }\end{array}$ \\
\hline 471 & Discovery & $\begin{array}{l}\text { SIBIA Neurosciences } \\
\text { Inc }\end{array}$ & SIB-1553A & $\begin{array}{l}\text { Neurological disease; } \\
\text { Parkinsons disease }\end{array}$ & $\begin{array}{l}\text { Nicotinic ACh } \\
\text { modulator }\end{array}$ & Antiparkinsonian \\
\hline 472 & $\begin{array}{l}\text { Phase } 2 \\
\text { Clinical } \\
\end{array}$ & $\begin{array}{l}\text { SIBIA Neurosciences } \\
\text { Inc }\end{array}$ & SIB-1553A & Alzheimers disease & $\begin{array}{l}\text { Nicotinic ACh } \\
\text { modulator }\end{array}$ & Antiparkinsonian \\
\hline 473 & $\begin{array}{l}\text { No } \\
\text { Development } \\
\text { Reported }\end{array}$ & $\begin{array}{l}\text { SIBIA Neurosciences } \\
\text { Inc }\end{array}$ & SIB-1765F & Alzheimers disease & Nicotinic ACh agonist & $\begin{array}{l}\text { Nootropic agent; } \\
\text { Antiparkinsonian }\end{array}$ \\
\hline 474 & Discovery & Schering-Plough Corp & Siclofen & $\begin{array}{l}\text { Neurodegenerative } \\
\text { disease }\end{array}$ & GABA B agonist & Neuroprotectant \\
\hline 478 & $\begin{array}{l}\text { No } \\
\text { Development } \\
\text { Reported }\end{array}$ & GlaxoSmithKline plc & SKF-74652 & $\begin{array}{l}\text { Alzheimers disease; } \\
\text { Neurodegenerative } \\
\text { disease }\end{array}$ & $\begin{array}{l}\text { Beta amyloid generation } \\
\text { inhibitor; Amyloid } \\
\text { protein deposition } \\
\text { inhibitor }\end{array}$ & Anti-amyloidogenic \\
\hline 479 & **Discovery & $\begin{array}{l}\text { SmithKline Beecham } \\
\text { plc }\end{array}$ & SKF-82958 & Parkinsons disease & Dopamine D1 agonist & Antiparkinsonian \\
\hline 480 & \begin{tabular}{|l|} 
No \\
Development \\
Reported \\
\end{tabular} & Synthelabo & SL-34.0026 & $\begin{array}{l}\text { Neurodegenerative } \\
\text { disease; Parkinsons } \\
\text { disease }\end{array}$ & MAO B inhibitor & Antiparkinsonian \\
\hline 481 & $\begin{array}{l}* * \text { Phase } 2 \\
\text { Clinical }\end{array}$ & Sanofi-Synthelabo & SL-65.0155 & Alzheimers disease & $\begin{array}{l}\text { 5-HT } 4 \text { antagonist; } \\
\text { 5-HT } 4 \text { agonist }\end{array}$ & $\begin{array}{l}\text { Neuroprotectant; } \\
\text { Nootropic agent }\end{array}$ \\
\hline 482 & Discontinued & Solcvay SA & SLV-308 & Parkinsons disease & $\begin{array}{l}\text { Dopamine D2 agonist; } \\
\text { Adrenoceptor agonist; } \\
\text { 5-HT 1a agonist }\end{array}$ & $\begin{array}{l}\text { Neuroprotectant; } \\
\text { Antiparkinsonian }\end{array}$ \\
\hline
\end{tabular}




\begin{tabular}{|c|c|c|c|c|c|c|}
\hline & $\begin{array}{l}\text { Highest dev. } \\
\text { status }\end{array}$ & Company & Drug & Indication & Mode of action & Drug effect \\
\hline 483 & $\begin{array}{l}* * \text { Phase } 1 \\
\text { Clinical }\end{array}$ & Solvay SA & SLV-314 & $\begin{array}{l}\text { Psychosis; } \\
\text { Schizophrenia }\end{array}$ & $\begin{array}{l}\text { 5-HT 1a receptor } \\
\text { modulator; Dopamine } \\
\text { D2 antagonist; 5-HT } \\
\text { uptake inhibitor }\end{array}$ & Antipsychotic \\
\hline 484 & $\begin{array}{l}* * \text { Phase } 1 \\
\text { Clinical }\end{array}$ & Solvay SA & SLV-319 & $\begin{array}{l}\text { Obesity; Psychosis; } \\
\text { Schizophrenia; } \\
\text { Metabolic disorder }\end{array}$ & $\begin{array}{l}\text { Dopamine D2 } \\
\text { antagonist; Cannabinoid } \\
\text { CB1 antagonist; 5-HT } \\
\text { 1a agonist }\end{array}$ & Antipsychotic \\
\hline 485 & $\begin{array}{l}* * \text { Phase } 2 \\
\text { Clinical }\end{array}$ & $\begin{array}{l}\text { Sumitomo } \\
\text { Pharmaceuticals Co } \\
\text { Ltd }\end{array}$ & SM-13496 & Schizophrenia & $\begin{array}{l}\text { 5-HT } 2 \text { antagonist; } \\
\text { Dopamine D2 } \\
\text { antagonist }\end{array}$ & Antipsychotic \\
\hline 486 & \begin{tabular}{|l|} 
No \\
Development \\
Reported \\
\end{tabular} & $\begin{array}{l}\text { Elan Pharmaceuticals } \\
\text { Inc }\end{array}$ & SNX-482 & $\begin{array}{l}\text { Neurodegenerative } \\
\text { disease }\end{array}$ & Calcium channel blocker & Nootropic agent \\
\hline 487 & Discovery & Supratek Pharma Inc & SP-(V5.2)C & $\begin{array}{l}\text { Neurodegenerative } \\
\text { disease }\end{array}$ & VEGF antagonist & $\begin{array}{l}\text { Anticancer; } \\
\text { Antiarrhythmic } \\
\text { agent }\end{array}$ \\
\hline 488 & Discovery & Celgene Corp & SPC-9766 & $\begin{array}{l}\text { Neurodegenerative } \\
\text { disease; Parkinsons } \\
\text { disease; Ischemia; } \\
\text { Cerebrovascular } \\
\text { ischemia } \\
\end{array}$ & $\begin{array}{l}\text { Jun } \mathrm{N} \text { terminal kinase } \\
\text { inhibitor }\end{array}$ & $\begin{array}{l}\text { Neuroprotectant; } \\
\text { Antiparkinsonian }\end{array}$ \\
\hline 489 & Discovery & \begin{tabular}{|l} 
Sanochemia \\
Pharmazeutika AG
\end{tabular} & SPH-1371 & $\begin{array}{l}\text { Alzheimers disease; } \\
\text { Dementia }\end{array}$ & Cholinesterase inhibitor & Neuroprotectant \\
\hline 490 & $* *$ Discovery & $\begin{array}{l}\text { Biofrontera } \\
\text { Pharmaceuticals } \\
\text { GmbH }\end{array}$ & $\begin{array}{l}\text { sphingomyelinase } \\
\text { inhibitors, } \\
\text { Biofrontera }\end{array}$ & $\begin{array}{l}\text { Neurodegenerative } \\
\text { disease }\end{array}$ & $\begin{array}{l}\text { Sphingomyelinase } \\
\text { inhibitor }\end{array}$ & \\
\hline 491 & **Discovery & $\begin{array}{l}\text { Sagami Chemical } \\
\text { Research Center }\end{array}$ & $\begin{array}{l}\text { sphingomyelinase } \\
\text { inhibitors, Taisho/ } \\
\text { Sagami }\end{array}$ & $\begin{array}{l}\text { Neurodegenerative } \\
\text { disease; } \\
\text { Cerebrovascular } \\
\text { ischemia }\end{array}$ & $\begin{array}{l}\text { Sphingomyelinase } \\
\text { inhibitor }\end{array}$ & $\begin{array}{l}\text { Neuroprotectant; } \\
\text { Nootropic agent }\end{array}$ \\
\hline 492 & Discovery & $\begin{array}{l}\text { Alviva } \\
\text { Biopharmaceuticals } \\
\text { Inc / Schwarz }\end{array}$ & SPM-914 & $\begin{array}{l}\text { Alzheimers disease; } \\
\text { Huntingtons } \\
\text { chorea; Motor } \\
\text { neurone disease; } \\
\text { Neurodegenerative } \\
\text { disease; Parkinsons } \\
\text { disease }\end{array}$ & Apoptosis inhibitor & \\
\hline 493 & Discovery & $\begin{array}{l}\text { Albert-Ludwigs- } \\
\text { Universität Freiburg }\end{array}$ & SPM-935 & $\begin{array}{l}\text { Neurodegenerative } \\
\text { disease }\end{array}$ & & Neuroprotectant \\
\hline 494 & $\begin{array}{l}* * \text { Phase } 2 \\
\text { Clinical }\end{array}$ & Sanofi-Synthelabo & SR-57667 & $\begin{array}{l}\text { Alzheimers disease; } \\
\text { Parkinsons disease }\end{array}$ & $\begin{array}{l}\text { Growth factor } \\
\text { stimulator; } \\
\text { anti-apoptotic }\end{array}$ & $\begin{array}{l}\text { Neuroprotectant; } \\
\text { Nootropic agent; } \\
\text { Antiparkinsonian }\end{array}$ \\
\hline 495 & $\begin{array}{l}\text { Phase } 2 \\
\text { Clinical }\end{array}$ & Wyeth & SRA-333 & Alzheimers disease & 5-HT 1a antagonist & Nootropic agent \\
\hline 496 & **Discovery & $\begin{array}{l}\text { Purdue Neuroscience } \\
\text { Corp }\end{array}$ & $\begin{array}{l}\text { SSNRAs, Purdue } \\
\text { Neuroscience/ } \\
\text { Pfizer }\end{array}$ & $\begin{array}{l}\text { Ocular disease; } \\
\text { Parkinsons } \\
\text { disease; Psychosis; } \\
\text { Central nervous } \\
\text { system disease; } \\
\text { Cerebrovascular } \\
\text { ischemia; Head } \\
\text { injury }\end{array}$ & $\begin{array}{l}\text { NMDA/Glycine } \\
\text { antagonist; NMDA } \\
\text { receptor antagonist }\end{array}$ & $\begin{array}{l}\text { Neuroprotectant; } \\
\text { Antipsychotic; } \\
\text { Antiparkinsonian }\end{array}$ \\
\hline
\end{tabular}




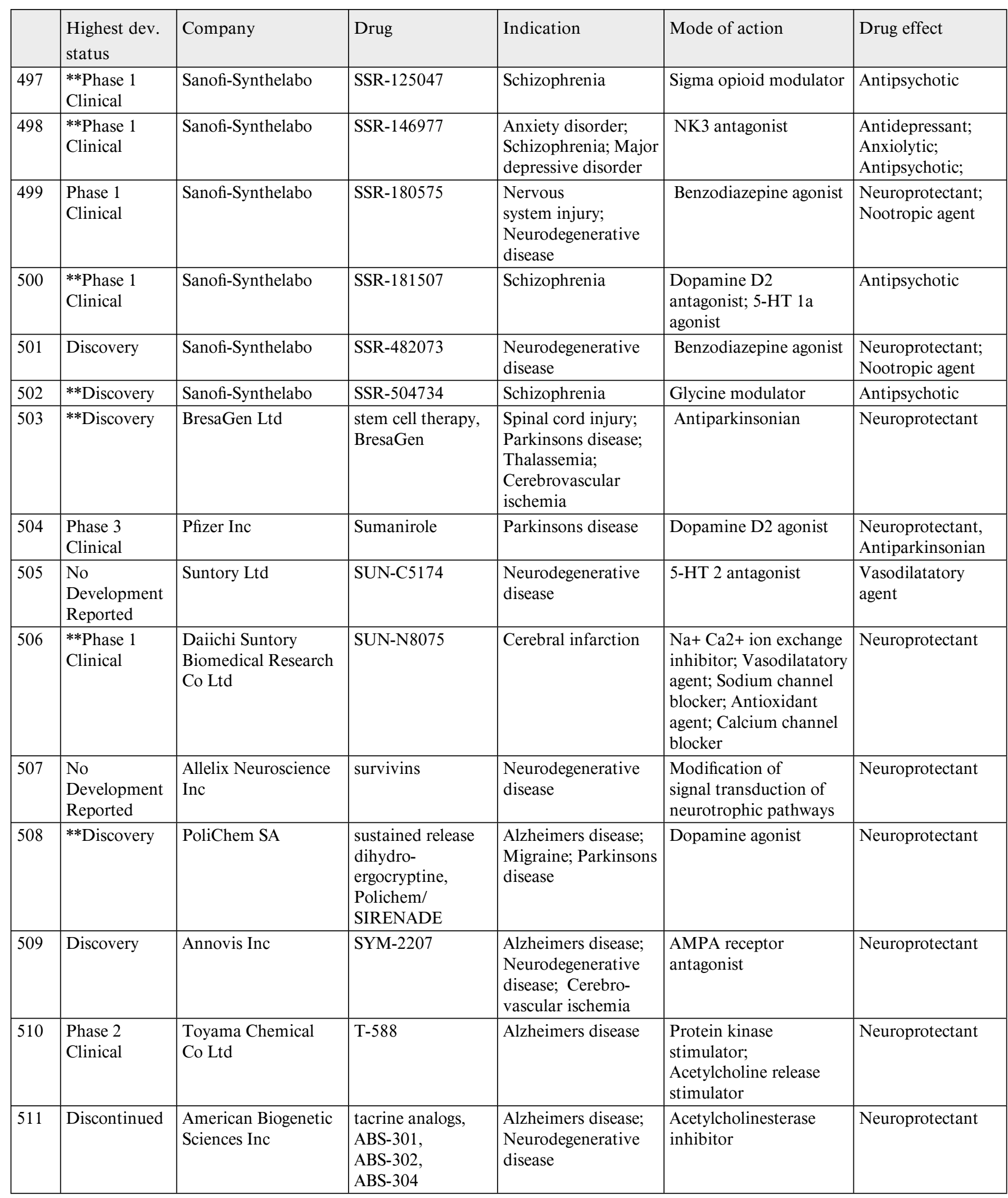




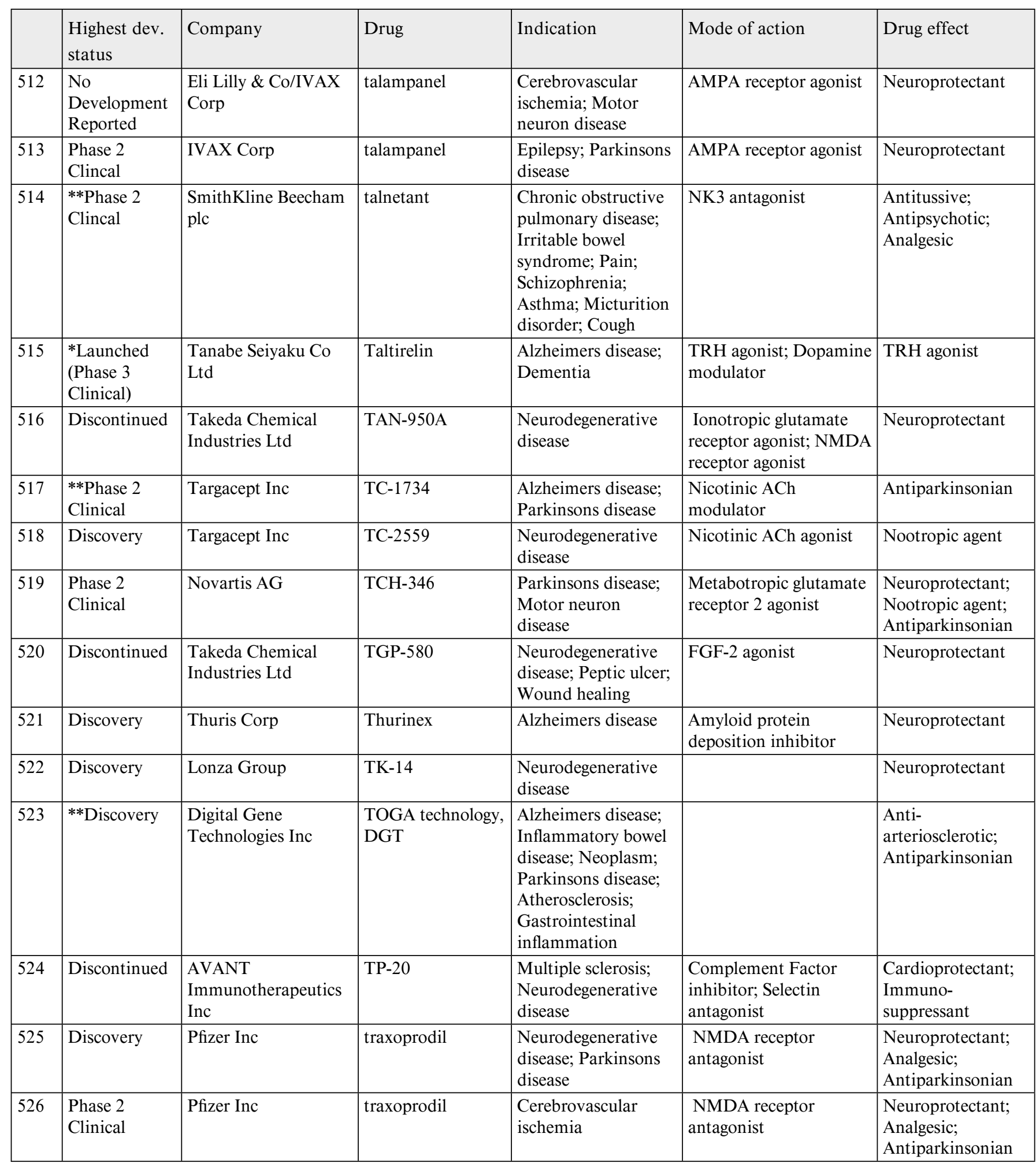




\begin{tabular}{|c|c|c|c|c|c|c|}
\hline & $\begin{array}{l}\text { Highest dev. } \\
\text { status }\end{array}$ & Company & Drug & Indication & Mode of action & Drug effect \\
\hline 527 & **Discovery & Pharmos Corp & $\begin{array}{l}\text { tricyclic } \\
\text { dextro- } \\
\text { cannabinoids, } \\
\text { Pharmos }\end{array}$ & $\begin{array}{l}\text { Neuropathic pain; } \\
\text { Inflammation; } \\
\text { Inflammatory } \\
\text { bowel disease; } \\
\text { Multiple sclerosis; } \\
\text { Neurodegenerative } \\
\text { disease; Parkinsons } \\
\text { disease; Rheumatoid } \\
\text { arthritis; } \\
\text { Autoimmune disease; } \\
\text { Cerebrovascular } \\
\text { ischemia; Nervous } \\
\text { system inflammation; } \\
\text { Brain injury }\end{array}$ & $\begin{array}{l}\text { Cyclooxygenase } \\
2 \text { inhibitor; } \\
\text { Immunomodulator; } \\
\text { Chemokine antagonist; } \\
\text { NMDA receptor } \\
\text { antagonist; Non- } \\
\text { steroidal anti- } \\
\text { inflammatory; } \\
\text { Cannabinoid agonist; } \\
\text { Cytokine modulator }\end{array}$ & $\begin{array}{l}\text { Neuroprotectant; } \\
\text { Analgesic; } \\
\text { Antiparkinsonian }\end{array}$ \\
\hline 529 & \begin{tabular}{|l|} 
No \\
Development \\
Reported
\end{tabular} & $\begin{array}{l}\text { Pharmacia \& Upjohn } \\
\text { Inc }\end{array}$ & U-74500A & $\begin{array}{l}\text { Neurodegenerative } \\
\text { disease }\end{array}$ & Aminosteroid & Neuroprotectant \\
\hline 530 & Discontinued & $\begin{array}{l}\text { Pharmacia \& Upjohn } \\
\text { Co }\end{array}$ & U-78517F & $\begin{array}{l}\text { Alzheimers disease; } \\
\text { Inflammation; } \\
\text { Neurodegenerative } \\
\text { disease; Cerebro- } \\
\text { vascular ischemia }\end{array}$ & $\begin{array}{l}\text { Lipid peroxidation } \\
\text { inhibitor }\end{array}$ & $\begin{array}{l}\text { Vasoprotectant; } \\
\text { Anti-inflammatory; } \\
\text { Antioxidant agent }\end{array}$ \\
\hline 531 & **Discovery & $\begin{array}{l}\text { Universidad } \\
\text { Complutense de } \\
\text { Madrid }\end{array}$ & UCM-3100 & $\begin{array}{l}\text { Psychiatric disorder; } \\
\text { Neurological disease }\end{array}$ & $\begin{array}{l}\text { 5-HT } 7 \text { receptor } \\
\text { modulator }\end{array}$ & \\
\hline 534 & $\begin{array}{l}\text { **Phase } 1 \\
\text { Clinical }\end{array}$ & Vernalis Group plc & V-2006 & Parkinsons disease & $\begin{array}{l}\text { Adenosine A2a } \\
\text { antagonist }\end{array}$ & Antiparkinsonian \\
\hline 535 & **Discovery & Novavax Inc & $\begin{array}{l}\text { vaccine (stroke), } \\
\text { Novavax }\end{array}$ & $\begin{array}{l}\text { Cerebrovascular } \\
\text { ischemia }\end{array}$ & Vaccine; CD62E agonist & Neuroprotectant \\
\hline 536 & $\begin{array}{l}* * \text { Research } \\
\text { Tool }\end{array}$ & $\begin{array}{l}\text { Royal Gist-Brocades } \\
\text { NV }\end{array}$ & vanoxerine & $\begin{array}{l}\text { Schizophrenia; } \\
\text { Cocaine addiction }\end{array}$ & $\begin{array}{l}\text { Dopamine uptake } \\
\text { inhibitor }\end{array}$ & Antipsychotic \\
\hline 537 & Research Tool & $\begin{array}{l}\text { US National Institute } \\
\text { on Drug Abuse }\end{array}$ & Vanoxerine & Schizophrenia & $\begin{array}{l}\text { Dopamine uptake } \\
\text { inhibitor }\end{array}$ & Antipsychotic \\
\hline 538 & **Discovery & Vasogen Inc & VP-025 & $\begin{array}{l}\text { Alzheimers disease; } \\
\text { Inflammation; Motor } \\
\text { neurone disease; } \\
\text { Parkinsons disease }\end{array}$ & Cytokine modulator & $\begin{array}{l}\text { Nootropic agent; } \\
\text { Anti-inflammatory }\end{array}$ \\
\hline
\end{tabular}




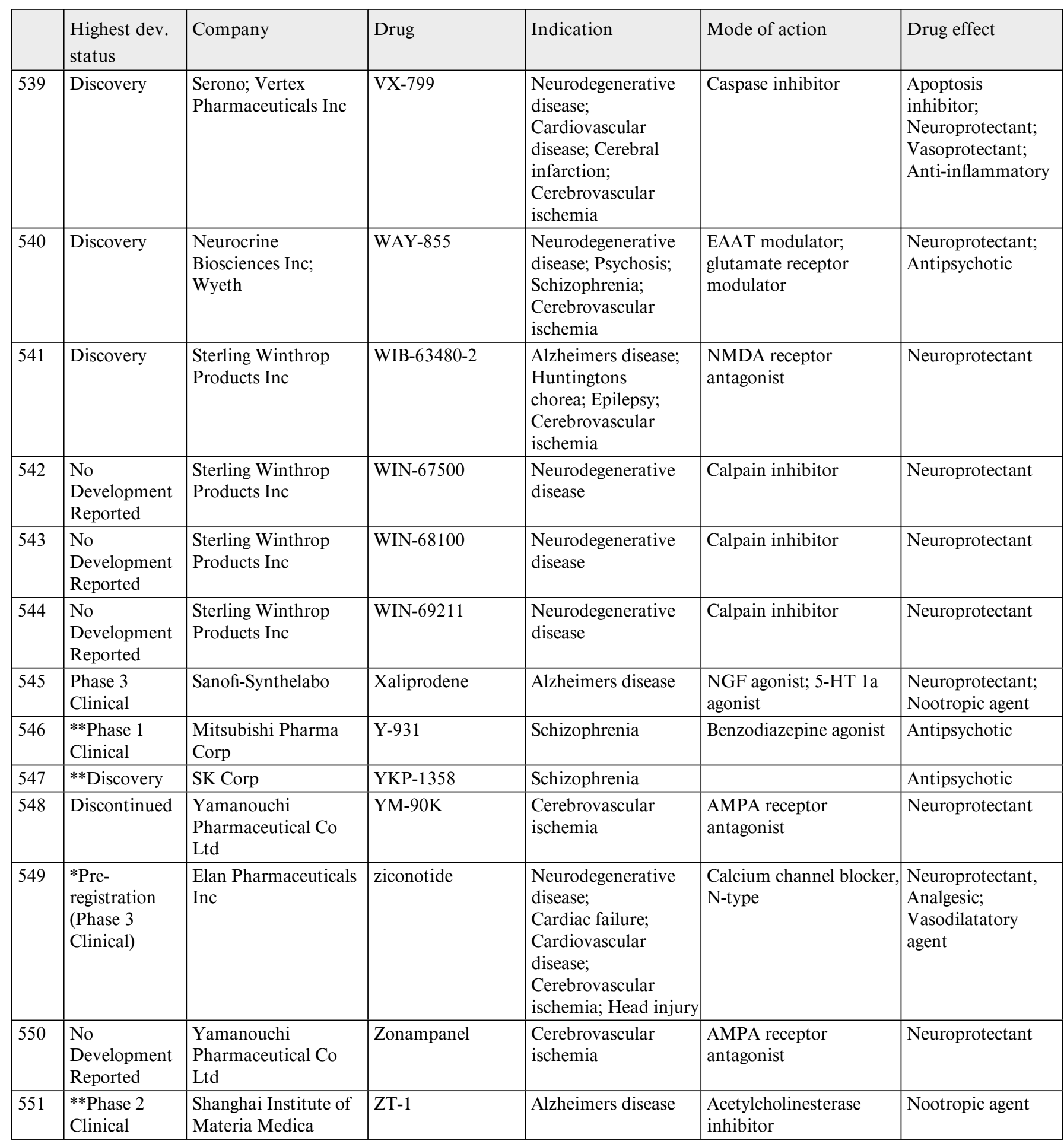




\section{Glossary}

No Development Reported: No evidence of continuing development has been reported for the past 18 months.

Discontinued: Confirmation from the company source that in-house development has been terminated.

Research Tool: Compounds that are not used as a drug, but needed to investigate the function of a specific compound, which might result in a drug.

Discovery: Late research state, preparation for human testing: adaptation of research chemical synthesis (mg) to larger scale $(\mathrm{kg})$, selection of salt form, selection of galenical form, design of clinical proof of concept studies, definition of endpoints, selection of biomarkers for clinical testing, additional safety testing, IND (investigational new drug) filing, clinical ethical review boards.

Phase 1: Clinical testing: tolerance in humans, repeated dosing, some escalation; proof of therapeutic concept or mechanism using scientific evaluation methods in a limited number of volunteers or patients.

Phase 2: Dose-finding studies, statistics, double blind studies.

Phase 3: Proof of efficacy, comparison to standard therapy, statistics, double blind studies with up to thousands of patients. Final phase of testing before registration and license to market.

\section{Sources}

'Investigational Drugs database, Copyright Current Drugs 2004, http://www.iddb3.com'

'The Final Neuroprotection Report, Bolt International Healthcare \& Pharmaceutical Research, February 2003'

\section{Disclaimer}

The author does not warrant or assume any legal liability or responsibility for the accuracy, completeness, or usefulness of the information in the article. It is not the intention of the author to provide medical advice or to promote or endorse any medical practice, test or program, but rather to provide readers with information to better understand neurodegenerative diseases. The author is not responsible for errors in or omissions of information contained in the article or any actions resulting from the use of such information. Readers are encouraged to confirm the information in the article with other reliable sources. 